\title{
Baltic Sea ecosystem response to various nutrient load scenarios in present and future climates
}

\author{
Sofia Saraiva' ${ }^{1} \cdot$ H. E. Markus Meier ${ }^{2,3} \cdot$ Helén Andersson $^{2} \cdot$ Anders Höglund $^{2} \cdot$ Christian Dieterich $^{2}$. \\ Matthias Gröger ${ }^{2} \cdot$ Robinson Hordoir ${ }^{2,4} \cdot$ Kari Eilola $^{2}$
}

Received: 4 July 2017 / Accepted: 25 June 2018 / Published online: 2 July 2018

(c) The Author(s) 2018

\begin{abstract}
The Baltic Sea is a shallow, semi-enclosed brackish sea suffering like many other coastal seas from eutrophication caused by human impact. Hence, nutrient load abatement strategies are intensively discussed. With the help of a high-resolution, coupled physical-biogeochemical circulation model we investigate the combined impact of changing nutrient loads from land and changing climate during the 21 st century as projected from a global climate model regionalized to the Baltic Sea region. Novel compared to previous studies are an extraordinary spin-up based upon historical reconstructions of atmospheric, nutrient load and runoff forcing, revised nutrient load scenarios and a comparison of nutrient load scenario simulations with and without changing climate. We found in almost all scenario simulations, with differing nutrient inputs, reduced eutrophication and improved ecological state compared to the reference period 1976-2005. This result is a long-lasting consequence of ongoing nutrient load reductions since the 1980s. Only in case of combined high-end nutrient load and climate scenarios, eutrophication is reinforced. Differences compared to earlier studies are explained by the experimental setup including nutrient loads during the historical period and by the projected nutrient loads. We found that the impact of warming climate may amplify the effects of eutrophication and primary production. However, effects of changing climate, within the range of considered greenhouse gas emission scenarios, are smaller than effects of considered nutrient load changes, in particular under low nutrient conditions. Hence, nutrient load reductions following the Baltic Sea Action Plan will lead to improved environmental conditions independently of future climate change.
\end{abstract}

Keywords Baltic Sea $\cdot$ Future climate scenarios $\cdot$ Future socio-economic scenarios

Sofia Saraiva

saraivadasneves@hotmail.com

1 Instituto Superior Técnico, Environment and Energy Section, University of Lisbon, Av. Rovisco Pais, 1, 1049-001 Lisbon, Portugal

2 Department of Research and Development, Swedish Meteorological and Hydrological Institute, 60176 Norrköping, Sweden

3 Department of Physical Oceanography and Instrumentation, Leibniz Institute for Baltic Sea Research Warnemnde, 18119 Rostock, Germany

4 Institute of Marine Research, Nordnesgaten 50, 5005 Bergen, Norway

\section{Introduction}

As eutrophication is regarded today as the most challenging environmental problem of the Baltic Sea (Boesch et al. 2006), nutrient load abatement strategies have been developed resulting into the so-called Baltic Sea Action Plan (BSAP) facilitated by the Helsinki Commission (HELCOM). The BSAP is a commitment of all Baltic Sea countries to reduce nutrient loads country wise (HELCOM 2007, 2013). The adopted maximum allowable loads of the BSAP were calculated by using a coupled physical-biogeochemical model for the Baltic Sea such that the nutrient load reductions met the targets of good environmental status. The scenario simulations assume that the climate in the Baltic Sea will not change. However, many studies suggest that changes in temperature, sea ice, salinity, stratification, runoff, etc. will affect biogeochemical cycling considerably (The BACC II, Team Author 2015). Hence, the BSAP will be perhaps 
less effective in future climate than under present conditions (Meier et al. 2011a, b; Neumann et al. 2012).

The more general research topic on the biogeochemical cycles sensitivity to changes in physical conditions due to future climate and to changes in nutrient supply from land and atmosphere due to human activity, was addressed in several recent studies (e.g. Meier et al. 2011a, b, 2012a, b, 2017; Friedland et al. 2012; Neumann et al. 2012; Omstedt et al. 2012; Ryabchenko et al. 2016). For this task, plausible transient scenario simulations are needed. The first transient simulations (1960-2100) for the marine environment of the Baltic Sea were carried out by Neumann (2010) who investigated the impact of changing climate on the marine ecosystem under two greenhouse gas emission scenarios A1B and B1 (Nakicenovic and Swart 2000). Meier et al. (2011a) presented results of an ensemble study using regionalized climate data from two global general circulation models (GCMs), three coupled physical-biogeochemical models for the Baltic Sea and a series of combined nutrient load and greenhouse gas emission scenarios (A1B and A2). In the latter study, the estimate of uncertainties in projections due to model biases in global and regional climate models, nutrient load scenarios and natural variability was an important, novel result. Later, similar approaches were presented also by (Friedland et al. 2012; Meier et al. 2012a, b; Neumann et al. 2012; Omstedt et al. 2012; Ryabchenko et al. 2016).

The results by Meier et al. (2011a) indicated that oxygen depletion in the Baltic Sea deep water will aggravate in future climate due to (1) enlarged nutrient loads due to increased runoff from land, (2) reduced air-sea oxygen fluxes and (3) intensified internal nutrient cycling. The warming of the sea mainly causes (2) and (3). (1) is a consequence of the intensified hydrological cycle in the Baltic Sea region in warmer climate. Nutrient load changes in Meier et al. (2011a) were calculated from the product of nutrient concentrations in river water and volume flow. Three scenarios for nutrient concentrations were then applied: BSAP, reference and "worst case (or business-as-usual). In the BSAP and "worst case scenarios the changes in nutrient concentrations in river flows were calculated as relative changes compared to observed nutrient concentrations averaged for the period 1995-2002 (Gustafsson et al. 2011). The latter serves as reference concentrations. Hence, in all three scenarios, nutrient loads will increase in time by higher runoff. Thus, the reductions of loads following the BSAP scenario will be much smaller than planned under present climate conditions. In the present study, future nutrient load scenarios (2006-2100) are revised. In the most optimistic nutrient scenario, BSAP is assumed but without any impacts of changing climate and the worst case scenario follows recent results from Zandersen et al. (2018). The method described in Zandersen et al. (2018) consists in the estimation of an impact factor due to future socio-economic changes, estimated based on the regional downscaling of globally defined Shared
Socio-economic Pathways (SSPs), (e.g. O'Neill et al. 2014; van Vuuren et al. 2011), to the Baltic Sea region. The worst case scenario assumes the most pessimistic socio-economic development estimated by Zandersen et al. (2018) in combination with the climate change effect calculated from a hydrological model E-HYPE (Hydrological Predictions for the Environment, http://hypeweb.smhi.se) in the reference scenario. Loads and runoff in this reference scenario are direct results from the hydrological model driven with the same regionalized GCM as used for the atmospheric forcing of the ocean model, assuming no changes in the socio-economic development. An ensemble of long-term simulations for present climate conditions is presented, using only one driving GCM. Uncertainties due to biases in GCMs are investigated thoroughly in an accompanied study (Saraiva et al. 2018).

This study presents new features on the experimental setup of the scenario simulations compared to earlier studies:

1. a major revision of the consistently calculated runoff and nutrient load scenarios including a BSAP without impact of changing climate;

2. a long-term spin-up simulation with reconstructed atmospheric and hydrological forcing since 1850 to calculate proper initial conditions for the deep water and sediment;

3. an improved Baltic Sea model version to reduce model biases;

4. a regionalization of an improved GCM from the Coupled Model Intercomparison Project 5 (CMIP5) of the Intergovernmental Panel of Climate Change (IPCC 2013) using two greenhouse gas emission scenarios corresponding to the Representative Concentration Pathways (RCPs), RCP 4.5 and RCP 8.5;

5. scenario simulations with three nutrient load scenarios under present and future climates to separate the impact of changing climate and changing nutrient loads.

The paper is organized as follows. In the next section the regional climate modeling approach is explained. We introduce the Baltic Sea model and the forcing data sets for the atmosphere, runoff and nutrient loads. The experimental setup including projections with and without changing climate is presented. In Sect. 3 the results for the historical period (1976-2005) and the future projections until 2100 are presented. We focus on the analysis of changing water temperature, salinity, and nutrient, oxygen and phytoplankton concentrations, primary production, nitrogen fixation, hypoxic area and cod reproductive volume (total volume of water with salinity higher than 11 and oxygen concentration higher than $2 \mathrm{mLL}^{-1}$ ). Finally, in Sects. 4 and 5 the results are discussed and some conclusions of the study are drawn, respectively. 


\section{Methods}

\subsection{Baltic Sea model}

This study makes use of a three-dimensional physicalbiogeochemical model RCO-SCOBI, which consists of the physical Rossby Centre Ocean (RCO) model (Meier et al. 2003) coupled with the Swedish Coastal and Ocean Biogeochemical (SCOBI) model (Eilola et al. 2009; AlmrothRosell et al. 2011). The model domain covers the Baltic Sea area, assuming an open boundary in the northern Kattegat, with a horizontal resolution of $3.7 \mathrm{~km}$ and vertical resolution of $3 \mathrm{~m}$, corresponding to 83 depth levels (Fig. 1). The biogeochemical model SCOBI describes the dynamics of nitrate, ammonium, phosphate, three phytoplankton groups (diatoms, flagellates and others, and cyanobacteria), zooplankton, separated $\mathrm{N}$ and $\mathrm{P}$ detritus, oxygen and hydrogen sulfide in the water column. RCO-SCOBI has been previously evaluated and applied in numerous long-term climate studies. For further details and a thorough evaluation the reader is referred to Meier et al. (2003, 2011b, 2012b); Eilola et al. (2009, 2011); Almroth-Rosell et al. (2011).

\subsection{Regional climate data sets}

The climate projections used in this study are based upon the results of the global GCM MPI-ESM-LR (https://www. mpimet.mpg.de) downscaled to the Baltic Sea region using the coupled atmosphere-ice-ocean model RCA4-NEMO with a horizontal resolution of $25 \mathrm{~km}$ (Dieterich et al. 2006; Wang et al. 2015; Gröger et al. 2015). The domains of the atmosphere and ocean models cover the EURO-CORDEX (Jacob et al. 2014) and Baltic and North seas, respectively. The method uses GCM results as initial and boundary conditions for the high-resolution regional climate model (RCM). In this way, the large-scale circulation is combined with regional processes in high resolution to provide more realistic atmospheric surface fields that are used as forcing for the physicalbiogeochemical Baltic Sea model. This method has been used in previous approaches, (e.g. Meier et al. 2012b).

\subsection{Projections with climate change}

We focus on the greenhouse gas concentration scenarios RCPs 4.5 and 8.5 (Moss et al. 2010; Detlef et al. 2011; Stocker et al. 2013) that have been used in IPCCs Fifth
Fig. 1 The Baltic Sea bathymetry, locations of river mouths, monitoring stations and sub-basins as defined in this study. In this study, the basin designated by Baltic proper comprises Arkona Basin, Bornholm Basin and Gotland Basin

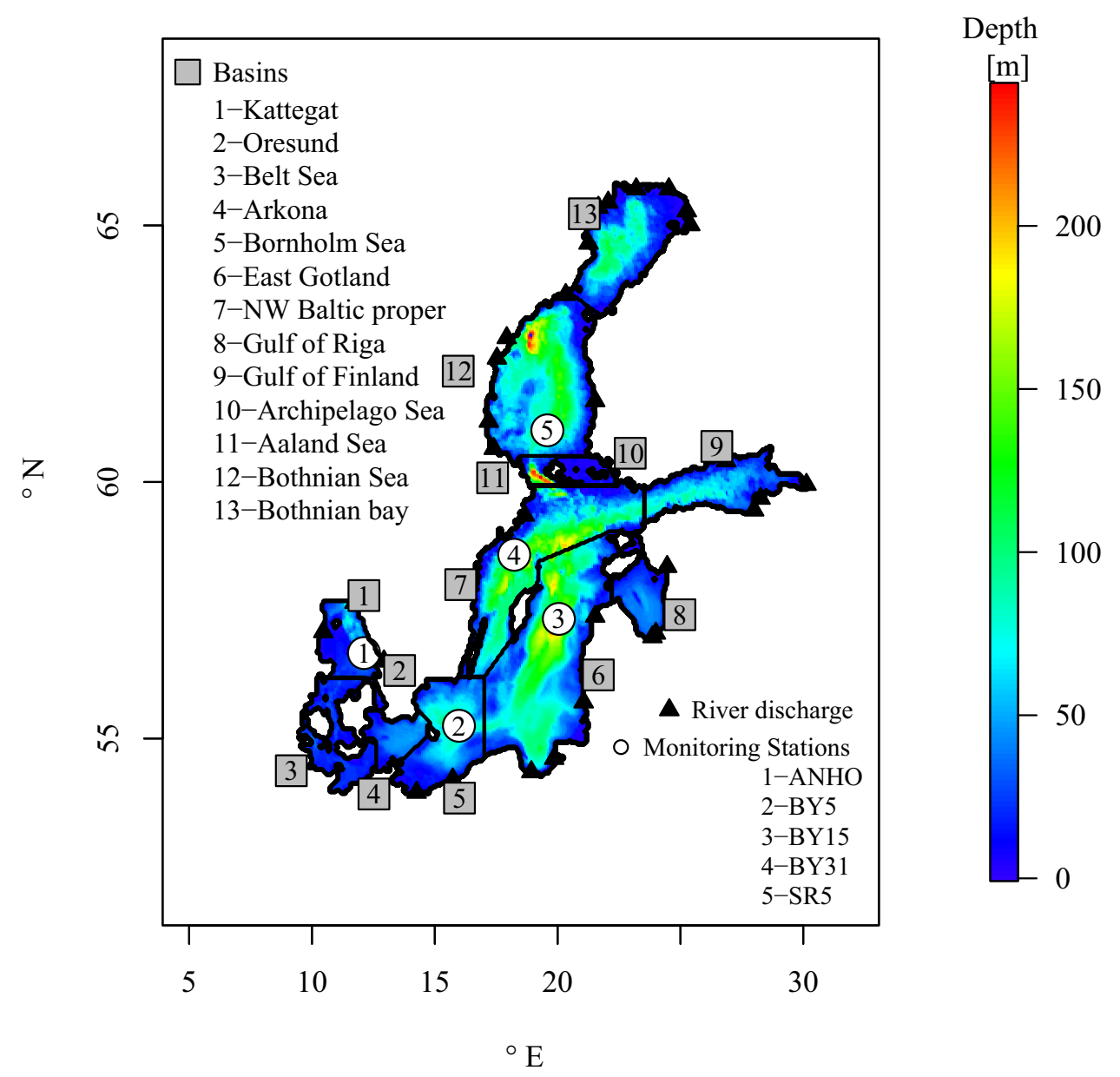


Assessment Report. They represent high-end and intermediate greenhouse gas concentration scenarios, respectively. Figure 2 represents the climatology (30-year average) of the main atmospheric variables in the different scenarios used as forcing of the 3D coupled physicalbiogeochemical model for the Baltic Sea. By comparison between EURO4M (European Reanalysis and Observations for Monitoring, http:// www.euro4m.eu/) and RCM results, the statistical distribution of the winds over sea agrees well up to $10 \mathrm{~ms}^{-1}$ but the models underestimate the winds above $10 \mathrm{~ms}^{-1}$ by a factor of 1.6. Therefore, a correction was made by multiplying the portion of the wind exceeding $10 \mathrm{~ms}^{-1}$ by 1.6 without altering the direction.

For 1976-2005, the RCM results are compared to independent synoptic observations from the Swedish Meteorological and Hydrological Institute (SMHI) (Fig. 2). Gridded data of sea level pressure, $2 \mathrm{~m}$ air temperature, $2 \mathrm{~m}$ relative humidity and total cloud cover are available since 1970 with a temporal resolution of three to six hours. In addition, 12 hourly accumulated precipitation fields are available at 06 and 18 UTC. Geostrophic wind speeds were calculated and reduced to $10 \mathrm{~m}$ wind speed by using a varying factor in the range between 0.5 and 0.6 , depending on the distance to the coast (Bumke and Hasse 1989). From Fig. 2 we conclude that the downscaled atmospheric forcing captures well the seasonal cycle of the properties and model values are within the error bars of observational data sets. Future projections result in higher temperature, precipitation and humidity, with larger changes projected by RCP 8.5 than by RCP 4.5 . Variables with less systematic changes are the fraction of clouds, wind speed and sea level pressure.

\subsection{Projections without climate change}

To better assess the impact of climate change on the Baltic Sea ecosystem, scenarios assuming no changing climate of atmospheric and hydrological forcing and sea level changes at the lateral boundary were built. For this we split the

Historical Period

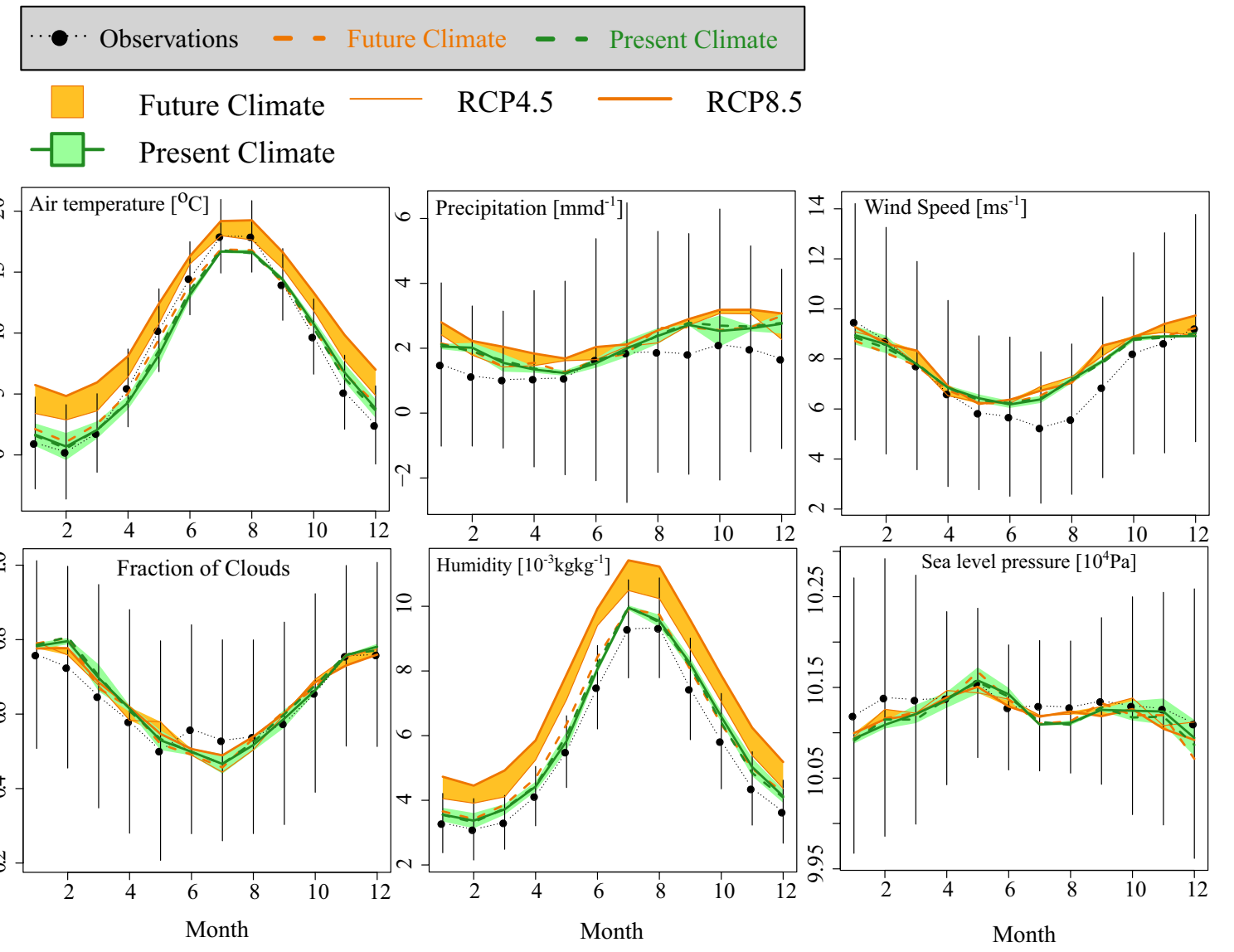

Fig. 2 Atmospheric variables in the different scenarios used as forcing of the 3D coupled physicalbiogeochemical model for the Baltic Sea at the monitoring station Gotland Deep (BY15): future (20692098), historical (1976-2005) and observed climatology. From the upper left to the lower right panel: air temperature in $2 \mathrm{~m}$ height, precipitation, wind speed in $10 \mathrm{~m}$ height, cloud fraction, specific humidity in $2 \mathrm{~m}$ height and mean sea level pressure 
forcing from the historical period (1961-2005) into intervals of 10 years and repeated these time series randomly between 1961 until 2100. In order to avoid sudden changes in atmospheric and oceanographic variables when connecting the different intervals, the separation instants were carefully chosen by selecting times that could fulfil, as close as possible, the following criteria: (1) sea level height at the boundary close to zero; (2) start in August to avoid strong gradients of sea surface pressure within the Baltic Sea area; (3) low wind velocity; (4) interval of 10 years to allow a realistic decadal variability. From the different possible instants, the selection was then made by choosing combinations with similar characteristics (small differences between atmospheric variables and sea level). The selected intervals were then randomly repeated to build complete data sets of atmospheric conditions between 1976 and 2100. The procedure was repeated three times to build three different "no climate change or present climate scenarios that form an ensemble of scenario simulations. The main atmospheric variables and its comparison with the results of the future climate scenario simulations can be found in Fig. 2.

\subsection{River runoff}

Runoff from the 30 largest rivers into the Baltic Sea (for the locations see Fig. 1) is considered (Fig. 3). The projected changes in discharge and nutrients to the Baltic Sea were simulated using the E-HYPE v3.2 model (Hundecha et al. 2016) updated to include water quality after the method of Donnelly et al. (2013) and using projected climate as described by Donnelly et al. (2017). Since E-HYPE simulations were performed under the same greenhouse gas concentration scenarios and driven with the same regionalized global climate model, the necessary consistency between runoff and atmospheric conditions (precipitation and air temperature) is guaranteed. Present climate scenarios assume in each river during the period 1975-2100 climatology of present conditions (1976-2005) simulated with E-HYPE driven by RCA4/MPI-ESM-LR. During the historical period simulated runoff is about $10 \%$ lower than observations by Bergström and Carlsson (1994), see also Meier and Kauker (2003). Future projections suggest an increase in the total runoff to the Baltic Sea (Fig. 3, upper left panel). The increase is significantly larger in RCP 8.5 than in RCP 4.5. The comparison between present and future climatology shows higher runoff during winter (Fig. 3, upper right panel). This shift in the seasonal pattern that is also more
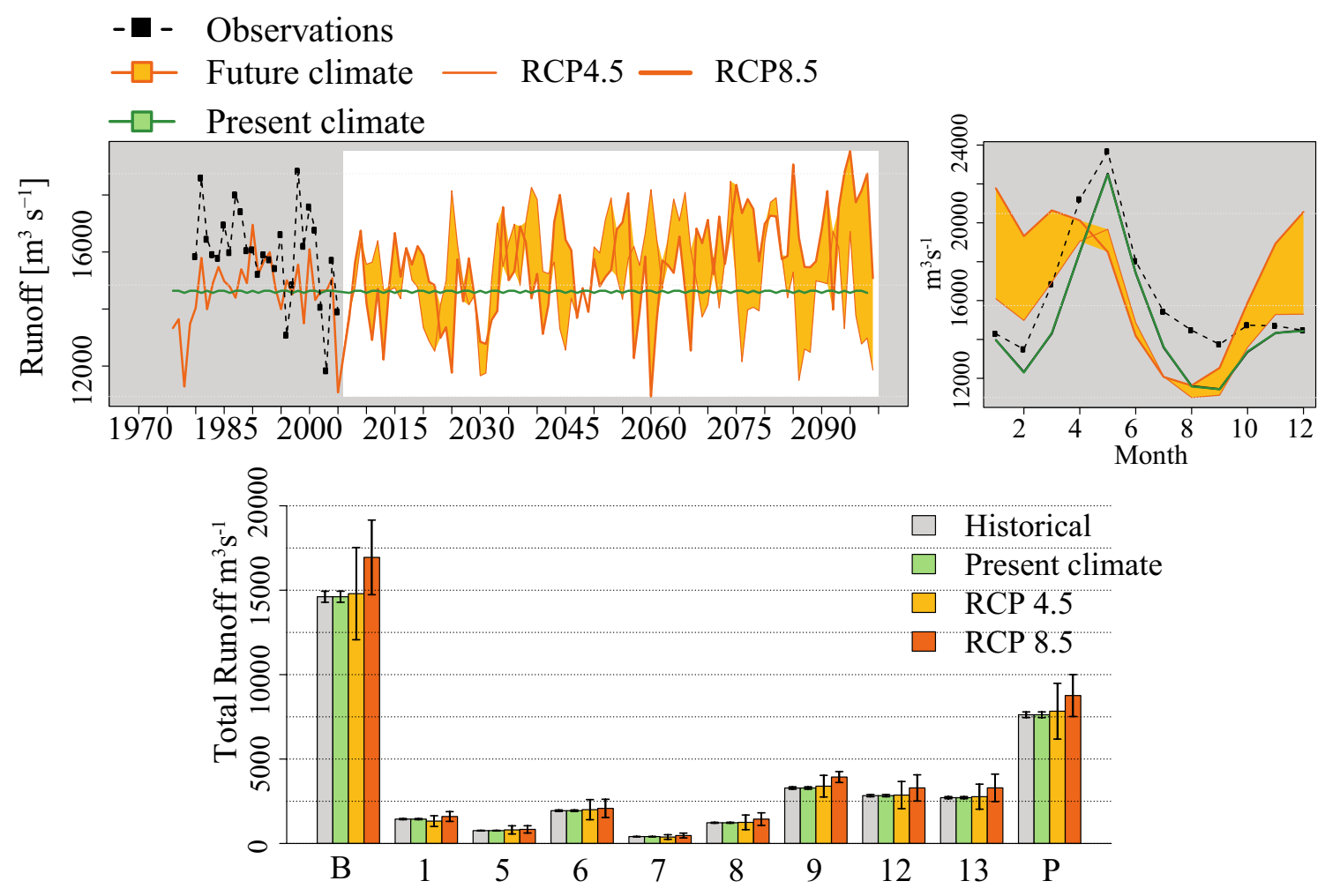

Fig. 3 Runoff projections to the Baltic Sea for 1975-2100 (upper left panel), mean seasonal cycle (upper right panel) and annual mean runoff in various sub-basins in present (1976-2005) and future climates (lower panel) 
pronounced in the RCP 8.5 than in the RCP 4.5 scenario is the result of changes in the snow conditions due to the increase in air temperature. Higher temperatures lead to an earlier snow melt causing larger runoff during winter. On average, annual runoff increases by about 1 and $15 \%$ in RCP 4.5 and RCP 8.5 , respectively, with a slightly higher increase in the northern (Gulf of Finland, Bothnian Sea and Bothnian Bay) than in the southern sub-basins (Baltic proper).

\subsection{Nutrient loads}

In this study, projections of nutrient concentrations in river discharges are related to socio-economic conditions in the future. SSPs are used in the climate research community to explore uncertainties in mitigation, adaptation and impacts associated with alternative climate and socio-economic futures (O'Neill et al. 2014). Here, three different SSPs are used to build three scenarios that cover a broad range of plausible nutrient loads. The different scenarios are described below, and the obtained nutrient loads are presented in Fig. 4. During the historical period (1976-2005) all simulations are forced with observed total nutrient loads from BED (Baltic Environmental Database, http://nest.su.se/ bed) including riverborne loads, point sources and atmospheric deposition.

1. Baltic Sea Action Plan (BSAP). This scenario is related with SSP1, sustainability or the green road, where there will be a commitment to achieve development goals, increasing environmental awareness and gradual move towards less resource intensive lifestyle (Zandersen et al. 2018). The translation of this SSP to the Baltic Sea is the
Future climate

$\begin{array}{llll}\text { BSAP } & \text { RCP4.5 } & - \text { RCP8.5 } & - \\ \text { Reference } & \text { RCP4.5 } & \text { BSAP } \\ \text { Rorst } & \text { RCP8.5 } & -\square- & \text { Reference } \\ \text { RCP4.5 } & - \text { RCP8.5 } & -\square-\text { Worst }\end{array}$

Present climate

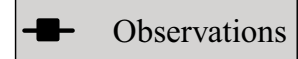

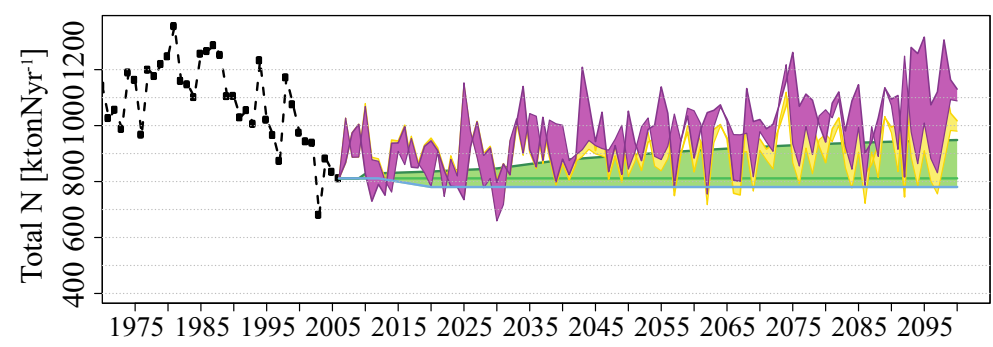
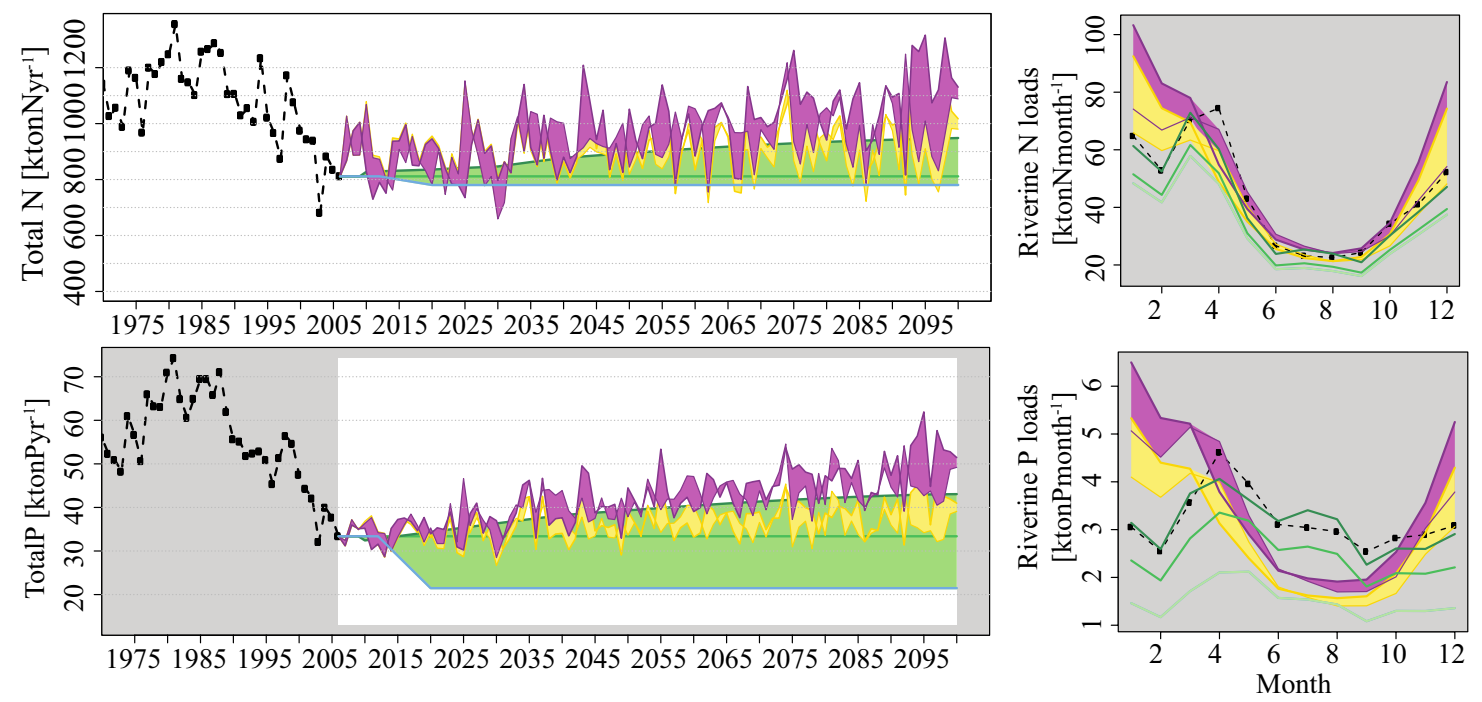

1975198519952005201520252035204520552065207520852095

RCP 8.5
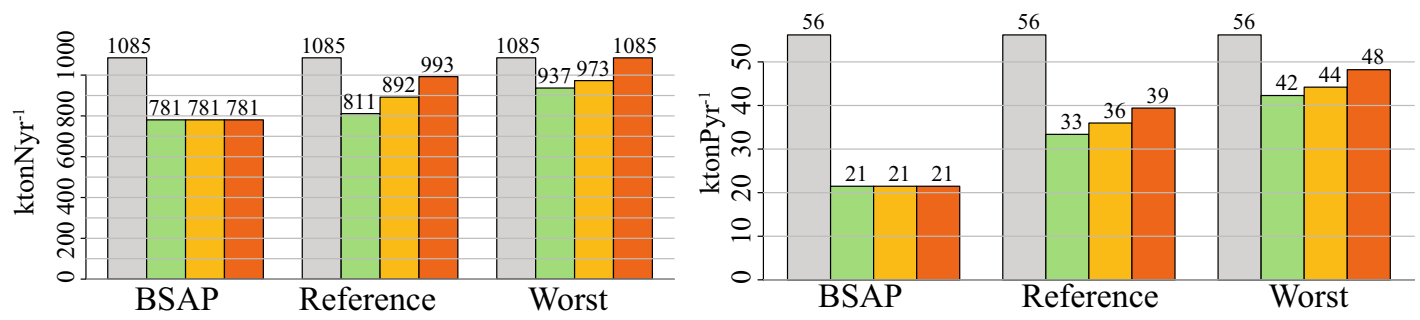

Fig. 4 Observed, present and projected total nutrient loads (nitrogen and phosphorus) to the Baltic Sea between 1970 and 2100 (upper left panels), mean seasonal cycle (upper right panels) and annual mean nutrient loads to the entire Baltic Sea in present (1976-2005) and

future (2069-2098) climates (lower panels). Note that in the model $30 \%$ of the river borne organic nitrogen supply is regarded as bioavailable but not listed here. The total loads include riverborne loads, point sources and atmospheric deposition 
BSAP proposed in the framework of HELCOM (HELCOM 2007, 2013). In this scenario, nutrient loads from rivers in different basins will linearly decrease from 2012 from current values (average 2010-2012), estimated by Svendsen et al. (2015), to the maximum allowable input defined in the plan until 2020. After that, the nutrient loads will remain constant until 2100. Atmospheric depositions are assumed to follow the BSAP as well.

2. Reference. This scenario assumes that nutrient sources to rivers and point sources and atmospheric deposition do not change over time, i.e., that they will not be controlled by additional measures. The nutrient load changes are thus only a consequence of changing climate (runoff and atmospheric conditions). This scenario uses the E-HYPE projections for nutrient loads under the two different greenhouse gas emission scenarios (RCP 4.5 and RCP 8.5) where the land and fertilizer usage, soil properties and sewage water treatment do not change over time. The assumptions of this scenario are based upon past developments (e.g., economic growth, demographic transition). Hence, the Reference scenario is related to SSP2, the middle of the road.

3. Worst. This scenario pretends to represent the worst possible scenario with increasing nutrient loads. It is based on SSP5 that assumes a fossil-fuelled development with accelerated globalisation and rapid development of developing countries (Zandersen et al. 2018). This scenario was built by combining the climate change effects caused by runoff changes (E-HYPE projections on nutrient loads for the two considered RCPs) with a socio-economic impact factor that summarizes the impact of socio-economic development on current nutrient loads. The impact factor is computed as relative difference between the nutrient load projections presented by Zandersen et al. (2018) and the present loads (Svendsen et al. 2015). Changed atmospheric depositions following the socio-economic development of this scenario are considered.

\subsection{Experimental setup}

The combinations of future (RCP 4.5 and RCP 8.5 ) and present climate scenarios and socio-economic scenarios (BSAP, Reference and Worst) result in 15 different model simulations. All the simulations have the same initial conditions, which were obtained from a longterm hindcast simulation (1850-2005). This simulation is based upon reconstructed atmospheric, hydrological, and nutrient load forcing using available historical observations (Meier et al. 2012c). Present climate simulations are always presented as an ensemble average of the three random realizations. In all figures the range between minus and plus one standard deviation is shown as shaded area.

In a first step, the historical period (1976-2005) will be compared with observations with the aim to validate and test the model performance and to assess biases induced by the usage of the atmospheric forcing from the regionalized GCM and E-HYPE runoff simulations. In a second step, the impacts of climate and nutrient load changes on the marine ecosystem are quantified by comparing various future scenarios (2006-2100) in terms of annual and seasonal changes in temperature, salinity, and nutrient, oxygen and phytoplankton concentrations, nitrogen fixation, primary production, hypoxic area and cod reproductive volume for the entire Baltic Sea and for individual sub-basins (for the locations see Fig. 1).

\section{Results}

\subsection{Historical period (1976-2005)}

The model performance is evaluated during the historical period by comparing the model with available observations. For the historical period, the comparison between the observed and simulated mean vertical profiles for temperature, salinity, nutrients and oxygen at two particular monitoring locations, i.e. Gotland Deep (BY15) and Bornholm Deep (BY5), is presented (Fig. 5). For all variables, the model results are in accordance with observations. The observed patterns are generally well described, and the mean simulated results are within the range of the variability of the observations. However, salinities in GCM driven simulations are slightly higher than in observations, which can be explained by the runoff from the E-HYPE model under GCM conditions, which is about $10 \%$ lower than the observations (Fig. 3). The horizontal and vertical patterns of the different variables are well described. At the bottom we can find on average higher salinity, phosphate and ammonium concentrations and lower oxygen concentrations. More details of the model validation and performance of the main biogeochemical processes can be found in (Eilola et al. 2009, 2011).

\subsection{Future projections}

\subsubsection{Temperature and salinity}

The climate model simulation results suggest that water temperature will increase with time as a direct consequence of the increase in air temperature projected by the driving GCM (Fig. 6). Baltic Sea average changes in sea 
Fig. 5 Simulated (orange solid line) and observed (black dotted line, data from BED) mean profiles of temperature, salinity, nutrients and oxygen at the monitoring stations BY5 and BY15 (for the locations see Fig. 1) for the historical (1976-2005) period. Observations are given at HELCOM standard depths and linearly interpolated between these depths. For observations (grey) and climate model results (orange) ranges between minus and plus one standard deviation of the temporal variability are shown as shaded areas. In addition, for present climate conditions an ensemble mean (green solid line) of three simulations representing the historical period 1961-2005 and the range between minus and plus one standard deviation among the ensemble members indicating the ensemble spread (green shaded area) are shown

surface temperature (SST) between future (2069-2098) and historical (1976-2005) conditions in RCP 4.5 and RCP 8.5 scenarios amount to about 1 and $2{ }^{\circ} \mathrm{C}$, respectively. Highest changes in SST are found in the central and northern parts of the Baltic Sea during spring (April, May, June) (Fig. 7). In the Bothnian Sea maximum changes exceed 1.5 and $3.5^{\circ} \mathrm{C}$ in RCP 4.5 and RCP 8.5 , respectively. This larger warming in the northern compared to the southern Baltic has been detected before (Meier et al. 2012b) and it is explained by changes in sea ice cover and surface albedo (Meier et al. 2011a; Wang et al. 2015) and by the reduced thermal convection under warmer and fresher conditions as discussed in Hordoir and Meier (2012). However, largest and smallest annual mean warming in volume averaged temperature is found in (1) the Gulf of Finland and Gulf of Riga and (2) Kattegat, respectively (Fig. 8). The latter is very likely an artefact of the lateral boundary conditions using climatological temperature and salinity profiles in case of inflow. Warming in the Bothnian Bay is about as large as in the Arkona Basin.

Due to the increased runoff volume averaged salinity decreases by about -0.4 and -1.2 in RCP 4.5 and RCP 8.5 , respectively (Fig. 8). These values are within the range of previously published projections summarized by the The BACC II, Team Author (2015). Natural variability is large causing large salinity differences between RCP 4.5 and RCP 8.5 at the end of the century whereas differences before 2070 are small (Fig. 6). Largest volume averaged salinity changes are found in the Gulf of Finland and Gulf of Riga and, in case of RCP 8.5, also in the Gotland Basin (Fig. 8). Again, smallest changes in volume averaged salinity in Kattegat might be an artefact caused using climatological profiles as boundary conditions. Nevertheless, changes in salinity are rather evenly distributed over the various sub-basins.

Although absolute values of changes vary between the two climate scenarios, the main pattern of the average profiles of temperature and salinity does not change significantly (Fig. 9) and strong stratification will still be one of the main characteristics of the Baltic Sea. In the ensemble of present climate simulation, built with the

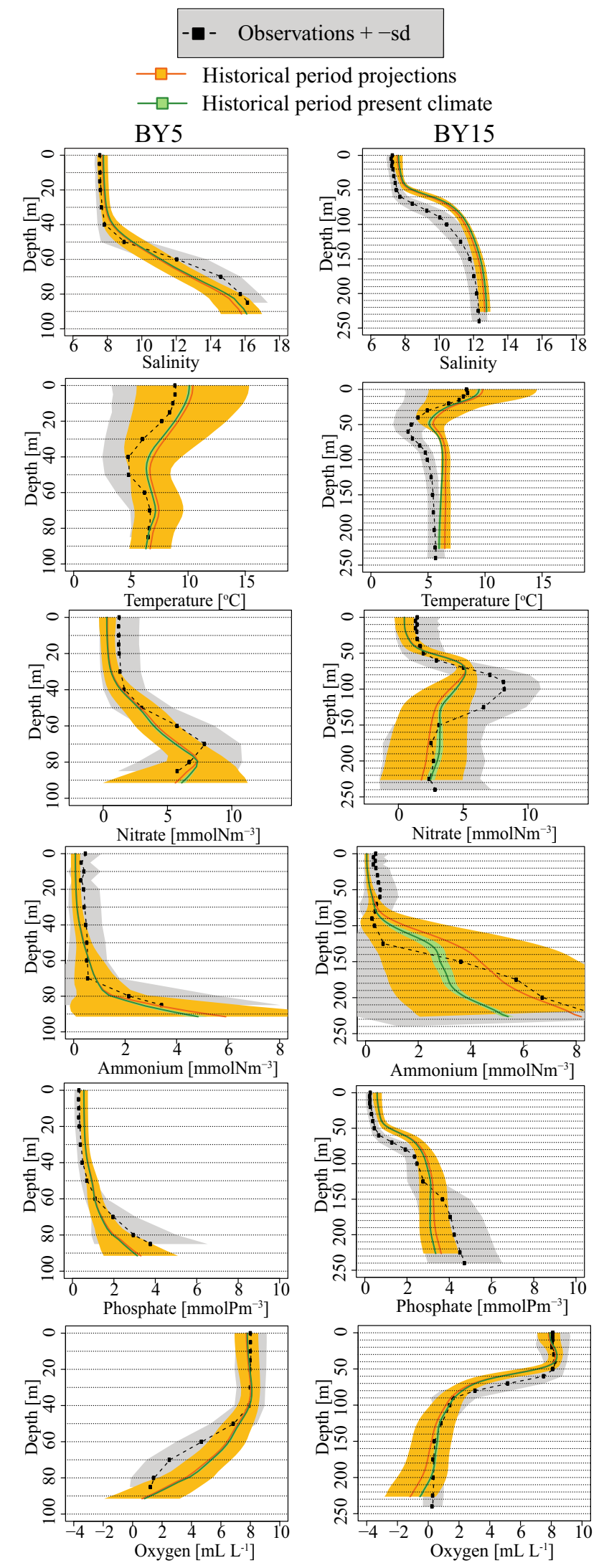




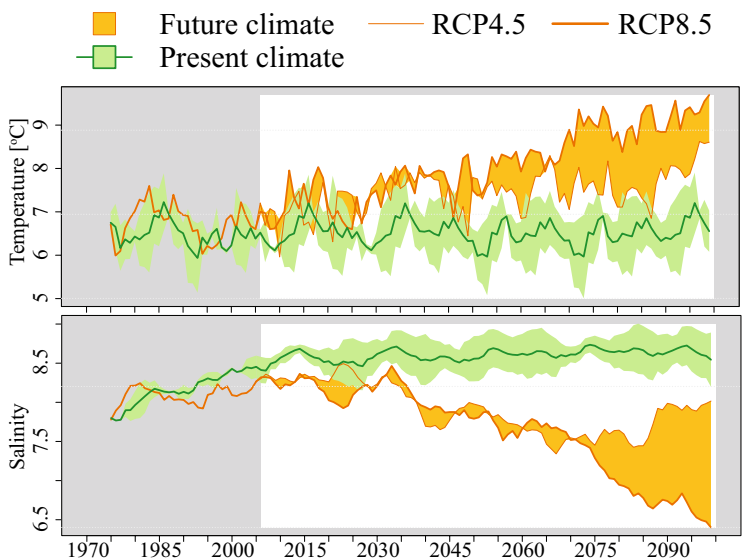

Fig. 6 Volume averaged water temperature and salinity in the Baltic Sea including Kattegat for the period 1975-2100 in present and future climates. For present climate conditions an ensemble mean (green line) of three simulations representing the historical period 1961-2005 and the standard deviation among the ensemble members (green shaded area) are shown. In addition, projections representing future evolution in time following RCP 4.5 (light orange line) and RCP 8.5 (thick orange line) are depicted. The orange shaded area is the range between RCP 4.5 and 8.5 illustrating the uncertainty in projected water temperature and salinity due to the unknown greenhouse gas emission scenario

repetition of weather conditions as observed during the past 1961-2005, changes between future and present volume integrated temperatures are small. These changes are caused by the long-term natural variability of the system and by artificial drifts as the model has not been started from an equilibrium under the given forcing such as the climatological runoff. In both RCP scenarios, the volume averaged temperature changes due to warming climate are significantly higher than natural variability, i.e. 1 and 2.5 ${ }^{\circ} \mathrm{C}$ in RCP 4.5 and RCP 8.5, respectively. Thus, the impact of climate change is considered to be significant (Fig. 8).
Volume averaged salinity, in turn, is projected to decrease. However, the absolute change in salinity in RCP 4.5 of -0.5 is only slightly higher than the absolute change in the present climate scenarios (+0.3) (Fig. 8), suggesting that the salinity changes are not statistically significant.

\subsubsection{Biogeochemical variables}

Nutrient (ammonium, nitrate and phosphate) projections for the Baltic Sea suggest a large range of different changes. Both changing nutrient loads and changing climate have important impacts on biogeochemical processes. First, the simulation results under reference nutrient loads and present climate conditions are investigated. Second, the changes of the nutrient cycles due to changing nutrient loads and/or changing climate are analyzed.

\subsubsection{Present-day forcing}

If nowadays nutrient load and climate conditions are maintained for the next decades, the model projects that nutrient concentrations averaged for the entire Baltic Sea will on average change (between 1976-2005 and 2069-2098) by about $-81 \%$ for ammonium, $+7 \%$ for nitrate and $-38 \%$ for phosphate (Fig. 10, middle panel). These changes are a consequence of the adjustment of the system to the considerable decrease in nutrient loads during the historical period due to the high residence time of nutrients in the water column and sediments (Fig. 4). As a result, there is a considerable time lag between the implementation and effectiveness of measures on nutrient loads.

The main consequence of the decrease in nutrients is a decrease in primary production (about $-34 \%$ ) and nitrogen fixation (about-64\%) (Fig. 10, middle panel) that also results in lower phytoplankton concentration of all simulated groups (Fig. 11). Oxygen concentration is, on average,
Fig. 7 Projected changes in seasonal mean sea surface temperatures in future climates according to RCP 4.5 (upper panels) and RCP 8.5 (lower panels)

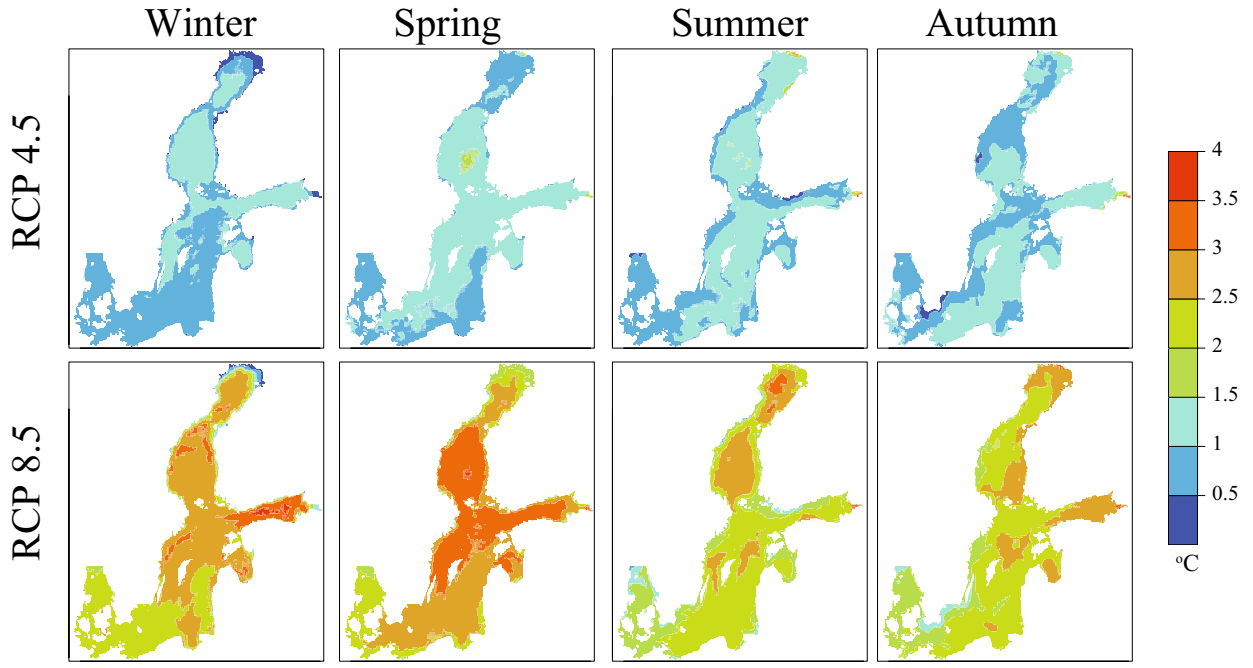




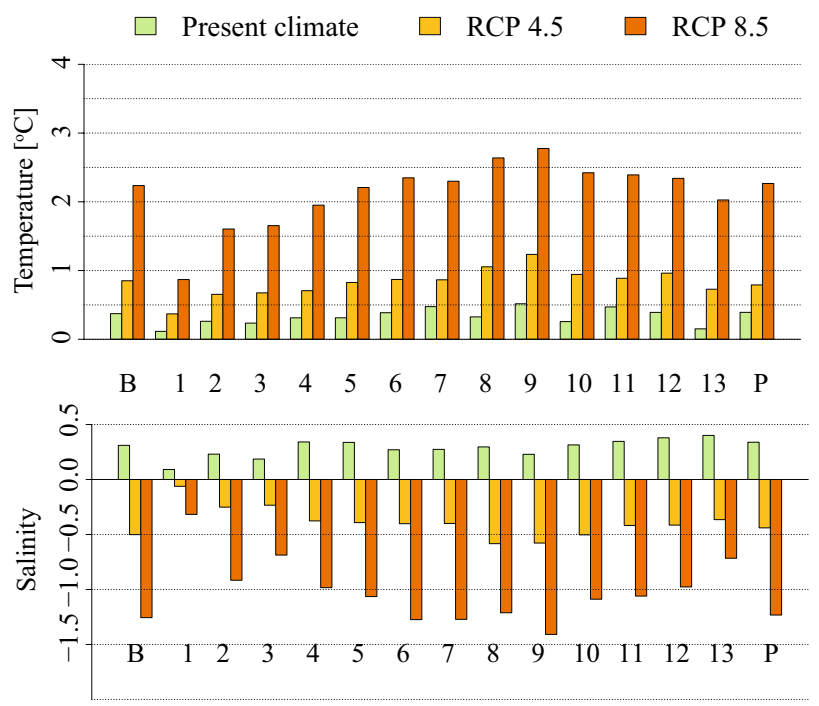

Fig. 8 Volume averaged temperature and salinity changes between future (2069-2098) and historical (1976-2005) periods in the two climate scenarios RCP 4.5 (yellow) and 8.5 (orange) in various subbasins. In addition, ensemble mean changes of three simulations representing present climate are shown. The sub-basin designated by $\mathrm{P}$ comprises Arkona Basin, Bornholm Basin and Gotland Basin and B comprises the entire Baltic Sea

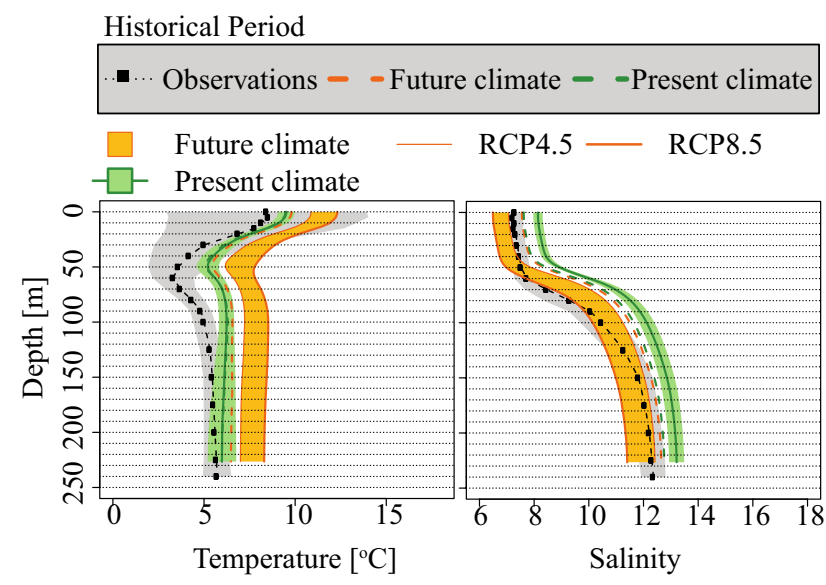

Fig. 9 Projected mean temperature and salinity profiles (orange solid line) for the period 2069-2098 in RCP 4.5 and 8.5 at the Gotland Deep station (BY15) compared to present climate (green solid line) and observations (black dotted line). In addition, mean profiles of the historical period (1976-2005) in transient (orange dashed line) and present (green dashed line) climates are shown. For present climate conditions an ensemble mean (green line) of three simulations representing the historical period 1961-2005 and the standard deviation among the ensemble members (green shaded area) are shown. In addition, projections representing future evolution in time following RCP 4.5 (light orange line) and RCP 8.5 (thick orange line) are depicted. The orange shaded area is the range between RCP 4.5 and 8.5 illustrating the uncertainty in projected water temperature and salinity due to the unknown greenhouse gas emission scenario

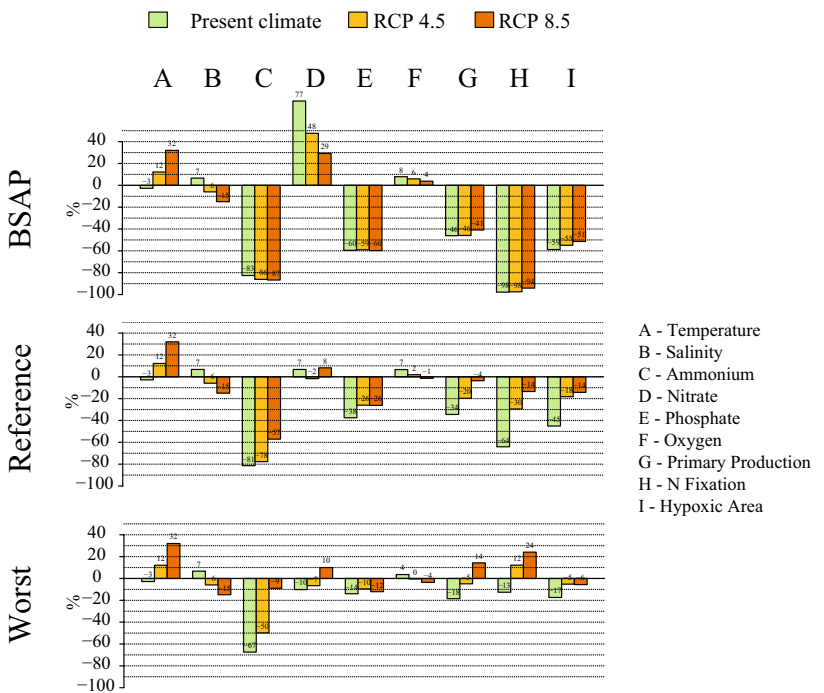

Fig. 10 Volume averaged, 30-year mean changes in temperature, salinity and nutrient, oxygen and phytoplankton concentrations in the entire Baltic Sea under the different climate and nutrient load scenarios: BSAP (upper panel), Reference (middle panel) and Worst (bottom panel). Relative temperature changes are based upon temperatures in ${ }^{\circ} \mathrm{C}$

projected to slightly increase by about $7 \%$, but the average hypoxic area would be about $45 \%$ smaller than during the historical period. Results show that by maintaining the present forcing conditions, the overall ecological state of the system would improve, mainly because the projected nutrient loads, even in the Worst scenario, would be still lower than the high levels during the past (Fig. 4).

\subsubsection{Impact of climate changes}

In general, most scenarios with changing climates (except Worst and RCP 8.5) show the same trend that will also lead to an improvement of the Baltic Sea ecological state, i.e. ammonium and phosphate concentrations decrease and nitrate and oxygen concentrations increasing in future compared with their concentrations in 2005 (Fig. 10). Consistently, phytoplankton and detritus concentrations, primary production and nitrogen fixation decrease over time. An exception arises by combining RCP 8.5 with the Worst scenario that induces an increase in primary production and phytoplankton concentrations.

In all scenarios we found a reduction in hypoxic area compared to the historical climate. However, it is important to note that hypoxic areas during the historical period are unprecedentedly large and by about $30 \%$ overestimated by the model compared to observations (Väli et al. 2013).

Although all scenario simulations show the same trends, its significances decrease with increasing warming because 
Fig. 11 Volume averaged nutrient, phytoplankton, oxygen and detritus concentrations, nitrogen fixation, primary production, cod reproductive volume and hypoxic area in the entire Baltic Sea in various scenario simulations

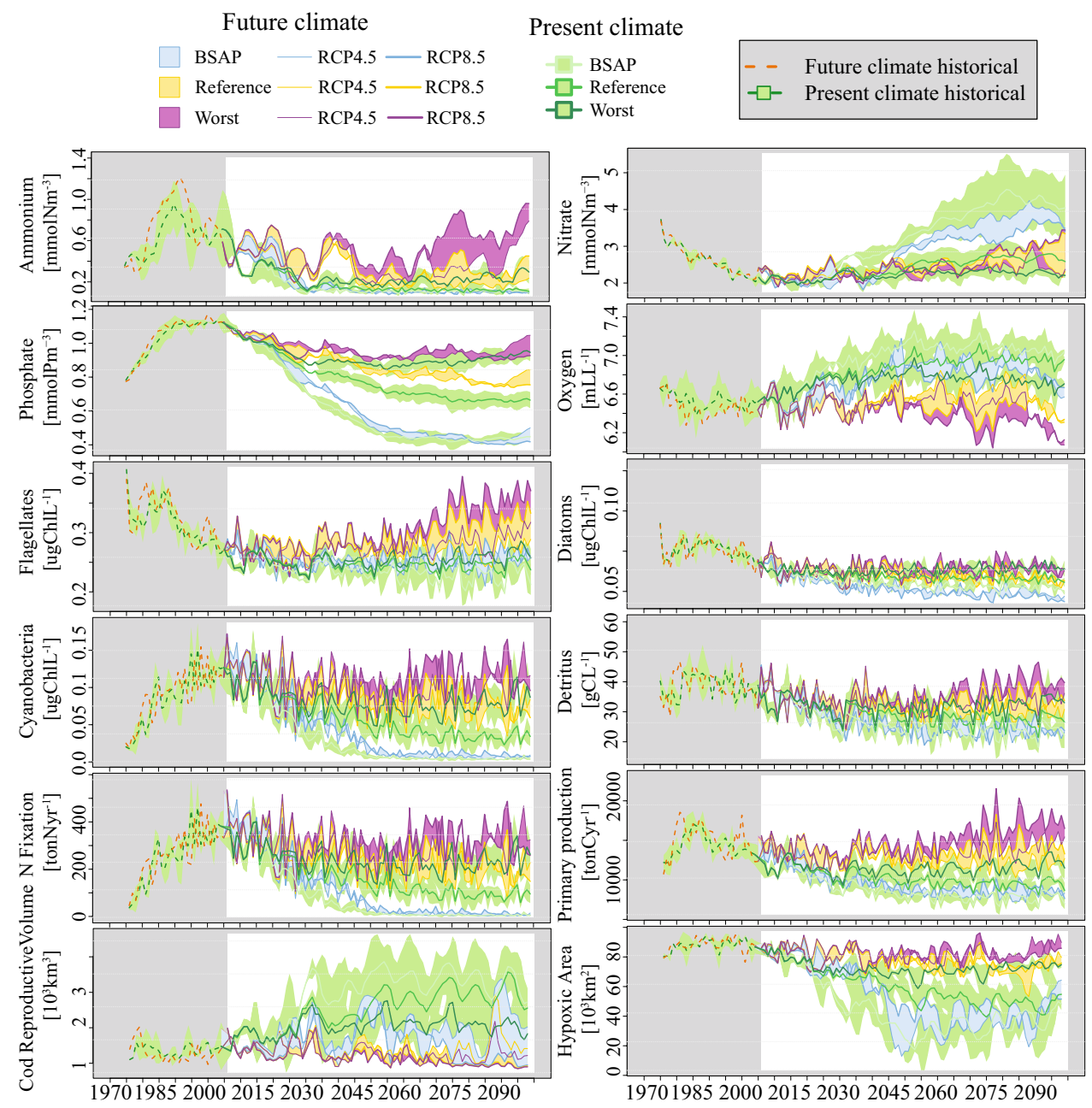

changing climate counteracts the future improvements of the ecological state due to the historical nutrient load reductions. Thus, present climate scenarios present higher changes, followed by RCP 4.5 and by RCP 8.5 .

\subsubsection{Impact of nutrient load changes}

Although similar trends are found, the impact of climate depends very much on the nutrient supply. The impacts of climate, i.e. differences between RCP 4.5 and RCP 8.5 for the same variable, are smaller in BSAP (Fig. 10, upper panel) and higher in the Worst scenario (Fig. 10, lower panel) compared with the Reference scenario (Fig. 10, middle panel). This is also noticeable from the comparison of long-term mean nutrient profiles (Fig. 12). Further, differences in profiles between scenarios are generally larger at the bottom than at the sea surface because nutrient fluxes between the water column and the sediment are extremely dependent on temperature and oxygen conditions.
Primary production and nitrogen fixation differ among scenario simulations, but the average seasonal patterns are maintained (Fig. 13). Two major blooms in primary production can be identified. One occurs during early spring, mainly dominated by diatoms and flagellates and others, and another one during late summer, related with cyanobacteria growth. The latter is also identified in the mean seasonal cycle of nitrogen fixation (Fig. 13, right panel). The comparison of the different scenario simulations in terms of these two processes (primary production and nitrogen fixation) suggests that the impact of changing nutrient loads is more important than the changes in climate. Clear differences can also be detected in the summer bottom concentration of oxygen (Fig. 14).

Under the BSAP in all climate scenarios, projected hypoxic area is about half of present day hypoxic area on average (Figs.10,11,14) and successively larger with increasing nutrient loads and warmer climate. In the combination of the worst scenario and RCP8.5, on average most of the Baltic proper (about $80 \%$ ) will have anoxic 
Fig. 12 Mean profiles of nutrient and oxygen concentrations at Gotland Deep (BY15) in the three nutrient load scenarios: BSAP (left panels), Reference (center panels), and Worst (right panels). Historical and future periods are 1976-2005 and 2069-2098, respectively

Historical Period

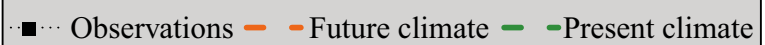

Future climate

$\square-$ Present climate
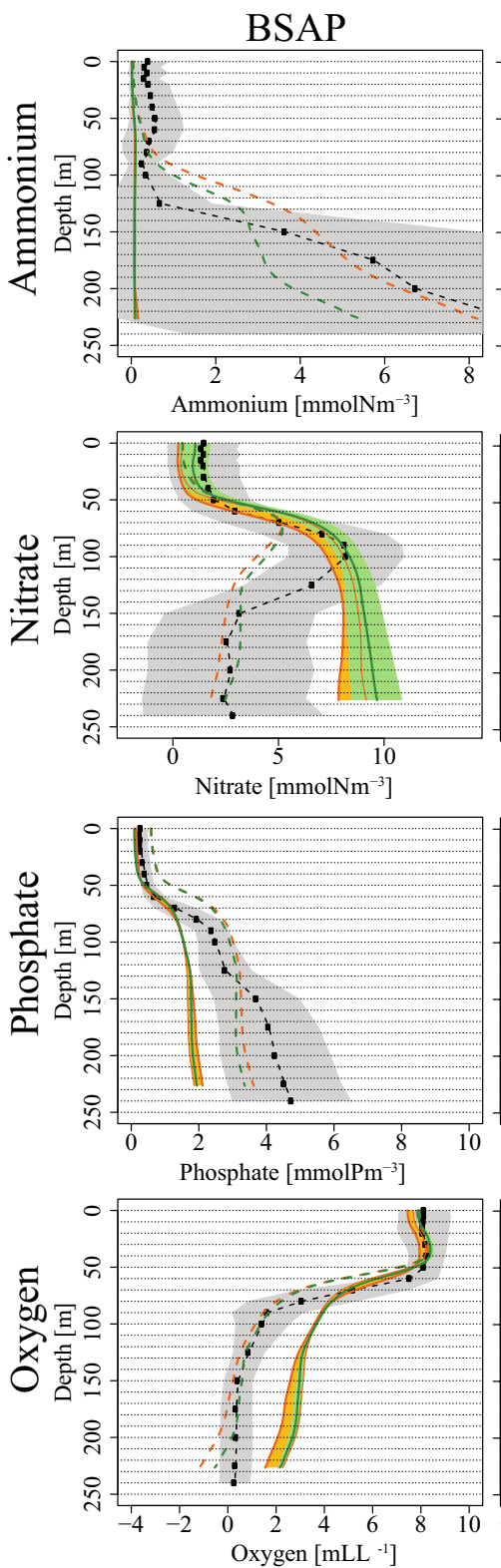

$\mathrm{RCP} 4.5-\mathrm{RCP} 8.5$
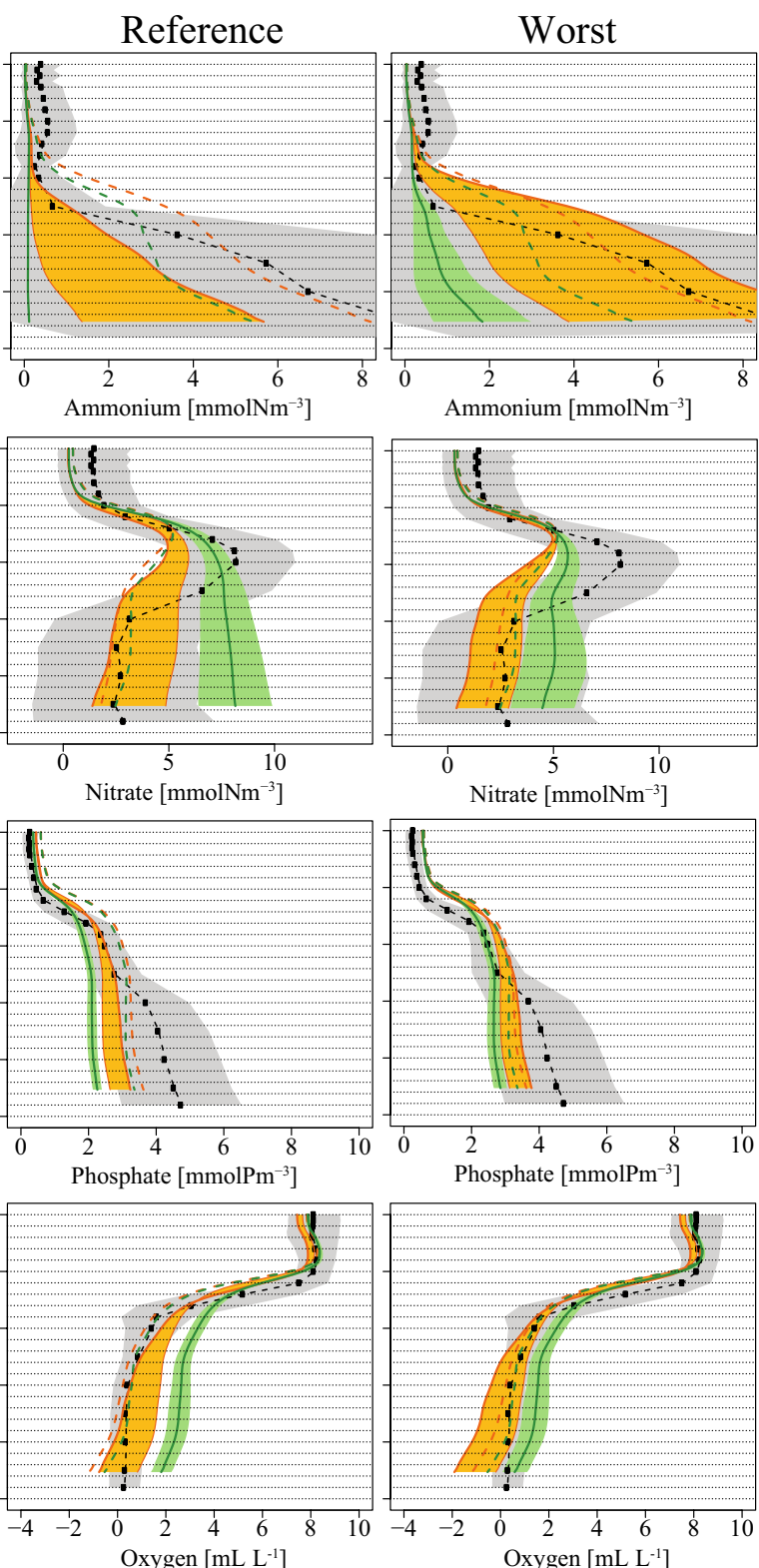

bottom conditions during summer. However, even in the latter scenario hypoxic area is still slightly smaller than present day hypoxic area (Fig. 10).

Although under BSAP oxygen concentrations increase in future climate, the increase in cod reproductive volume is modest because the impact of decreasing salinity is overwhelming (Fig. 11). Much larger cod reproductive volumes are found under present climate conditions.

It is also important to note that the response in biogeochemical cycles to changing climate and changing nutrient loads differ between the various sub-basins (Fig. 15). Relative changes between sub-basins are much larger in biogeochemical variables than for temperature or salinity (Fig. 8). In the BSAP scenario the largest increases in oxygen concentrations occur in the Eastern and North-Western Gotland basins, independent of the applied climate scenario. Therefore, phosphate and ammonium concentrations decrease, and nitrate concentrations increase in the Gotland Basin. However, for phosphate concentrations significant changes are also found in the northern (Gulf of Riga, Gulf of Finland, 


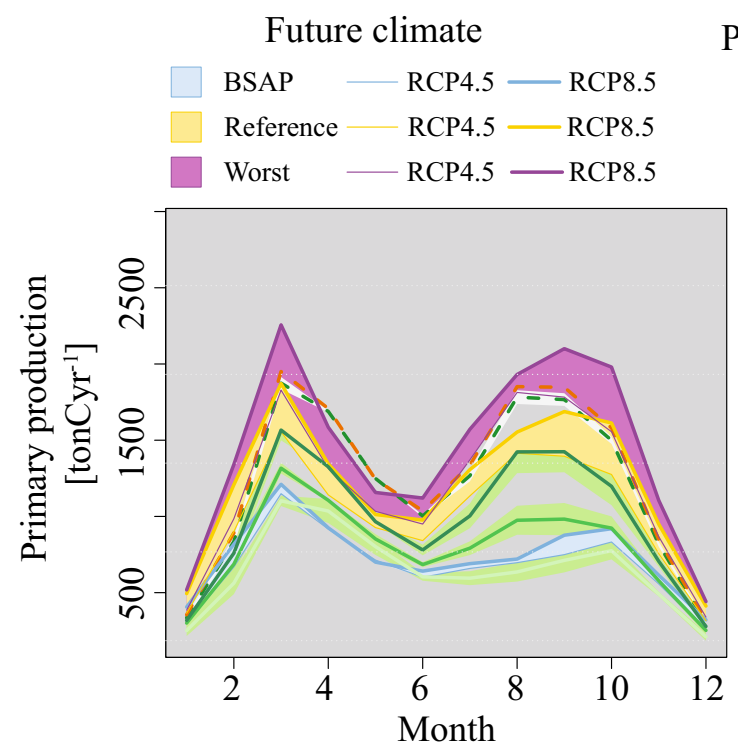

Fig. 13 Mean seasonal cycle in volume averaged primary production and nitrogen fixation average in various climate and nutrient load scenario simulations. Historical and future periods are 1976-2005 and

Archipelago Sea, land Sea and Bothnian Sea) and southern sub-basins (Arkona and Bornholmbasins). Indeed, earlier studies suggested that the Bothnian Sea is an important sink for phosphate exported from the Gotland Basin towards the north (Liu et al. 2017). Hence, changes in phosphate concentrations in the Gotland Basin should affect the Bothnian Sea as well. In the combined future climate and Worst scenarios relative changes in phosphate concentrations are largest in the Gulf of Riga, Gulf of Finland, Archipelago Sea and Bothnian Bay emphasizing again the important role of the eastern and northern sub-basins for the phosphorus cycling. In addition, one should note that the mouths of the rivers with the largest nutrient loads are in the eastern sub-basins and the Baltic proper (Fig. 1).

\section{Discussion}

In this study, an ensemble of 15 scenario simulations were performed by combining different future climate scenarios, present climate and nutrient load projections for the $21 \mathrm{st}$ century. The transient simulations under present climate conditions are forced by a repetition of past atmospheric conditions of 10-year time slices and, in principle, enable the estimation of natural variability of water temperature and salinity. However, there are systematic drifts in the simulations under present climate conditions indicated by a temperature and salinity difference between future (2069-2098) and historical (1976-2005) periods of $+0.4{ }^{\circ} \mathrm{C}$ and +0.3 , respectively (Fig. 8). For salinity the bias is very likely

\section{Present climate}
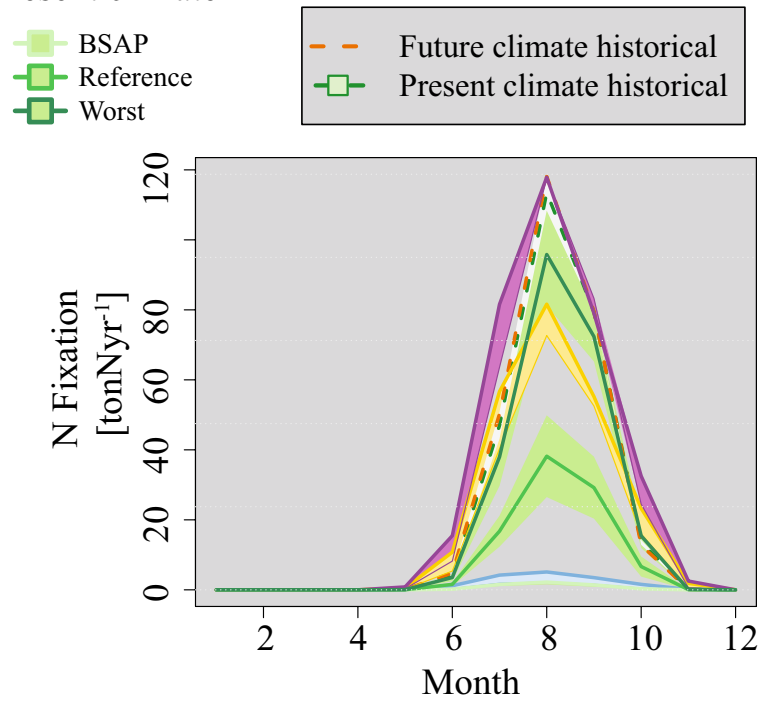

2069-2098, respectively. Green and orange dashed lines indicate the historical period of the present and future climate simulation, respectively

caused by the method to compute the atmospheric forcing and sea level variations at the lateral boundary in Kattegat. On average, every 100 years a stagnation period of about 10-year duration occurs, like the observed one in 1983-1992 (Schimanke and Meier 2016). As we have chosen 10-year long time slices of atmospheric and sea level forcing, stagnation periods do not occur in our simulations and in addition, the switches in the forcing usually generates saltwater inflows. Hence, we found in our transient present climate simulation a drift to higher salinity.

The future climate projections show an increase in air temperature and total runoff to the Baltic Sea. These changes have an impact on physical and consequently biogeochemical variables of the system. Higher temperatures imply an acceleration of all biogeochemical processes (e.g. phytoplankton growth, remineralization, etc.), but also have the indirect effect of increased runoff and reduced salinities. Increases in water temperatures by about +1 and $+2{ }^{\circ} \mathrm{C}$ in RCP 4.5 and RCP 8.5, respectively, are considered to be significant and above the natural variability of the system (Fig. 8).

On average, salinity will decrease by -0.4 and -1.2 in RCP 4.5 and RCP 8.5 , respectively, due to higher runoff but only changes in RCP 8.5 are significant as they are clearly above the range found in the present climate ensemble.

The changes between future and past concentrations of biogeochemical variables also reflect the adjustment of the system to the nutrient load reduction occurred during the historical period due to the high residence time in the system. The response time scale amounts to about 30 years 


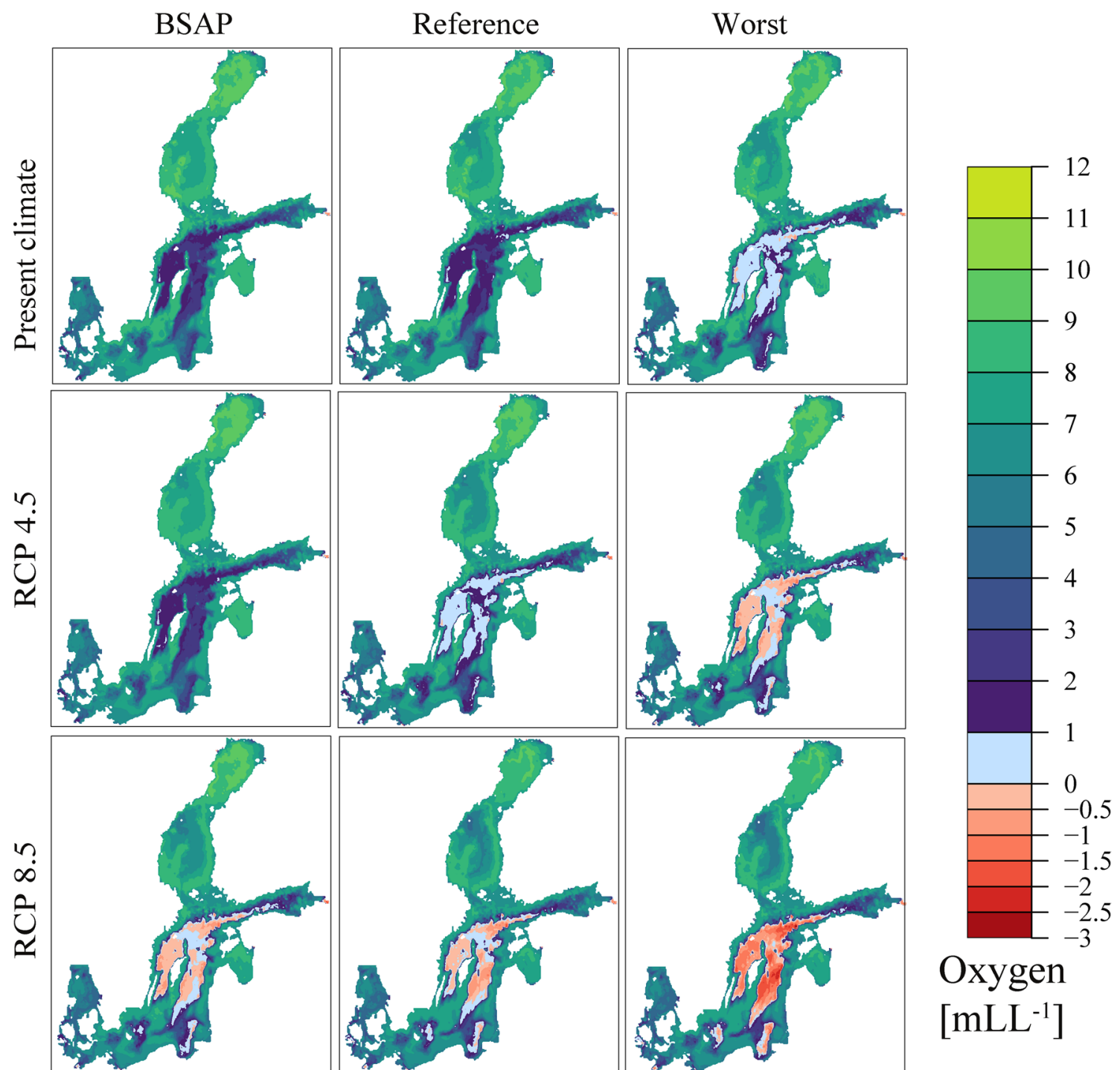

Fig. 14 Projected future (2069-2098) bottom oxygen concentrations during summer (average 2069-2098) in the different nutrient (BSAP, Reference and Worst) and climate scenarios (Present climate, RCP 4.5, RCP 8.5)

for the deep water renewal (Fig. 6) and is perhaps even longer for the phosphorus cycle including the sediment (Fig. 11). In fact, nutrient load projections assumed for the next 100 years do not reach the high levels from the past, even in the Worst scenario (Fig. 4).

Therefore, model projections suggest in all scenarios an overall improvement or at least maintenance of the ecological state of the Baltic Sea with a reduction of nutrient concentrations, primary production and nitrogen fixation compared to the period 1985-2005. In addition, slightly higher oxygen concentrations and a reduction in hypoxic area are found.

As in the various scenarios, the nitrogen to phosphorus ratio in the nutrient supply increases in the future compared to the historical period (Fig. 4), nitrogen fixation will very likely be further reduced. Nevertheless, there are very significant differences between scenarios that deserve a closer look. Under the assumption of BSAP, improvements are very pronounced, and the impact of changing climate does not play a significant role. Under successively higher nutrient loads (e.g. in Worst), climate changes become relatively more important and determinant in the future state of the ecosystem compared to conditions with smaller loads (e.g. in BSAP). Hence, the response of biogeochemical cycles to warming climate under various nutrient load scenarios is nonlinear.

The importance of climate change for the differences between future and present concentrations/fluxes can also be assessed by comparing its change directly with the present climate scenario simulations as shown in Fig. 16. 
Fig. 15 Volume averaged changes in ammonium, nitrate, phosphate and oxygen concentrations between future (2068-2098) and historical (1976-2005) periods in the different nutrient (BSAP, Reference and Worst) and climate scenarios (Present climate, RCP 4.5, RCP 8.5). The sub-basins are shown in Fig.1. The subbasins designated by $\mathrm{B}$ and $\mathrm{P}$ are the entire Baltic Sea and the Baltic proper (comprising Arkona Basin, Bornholm Basin and Gotland Basin), respectively

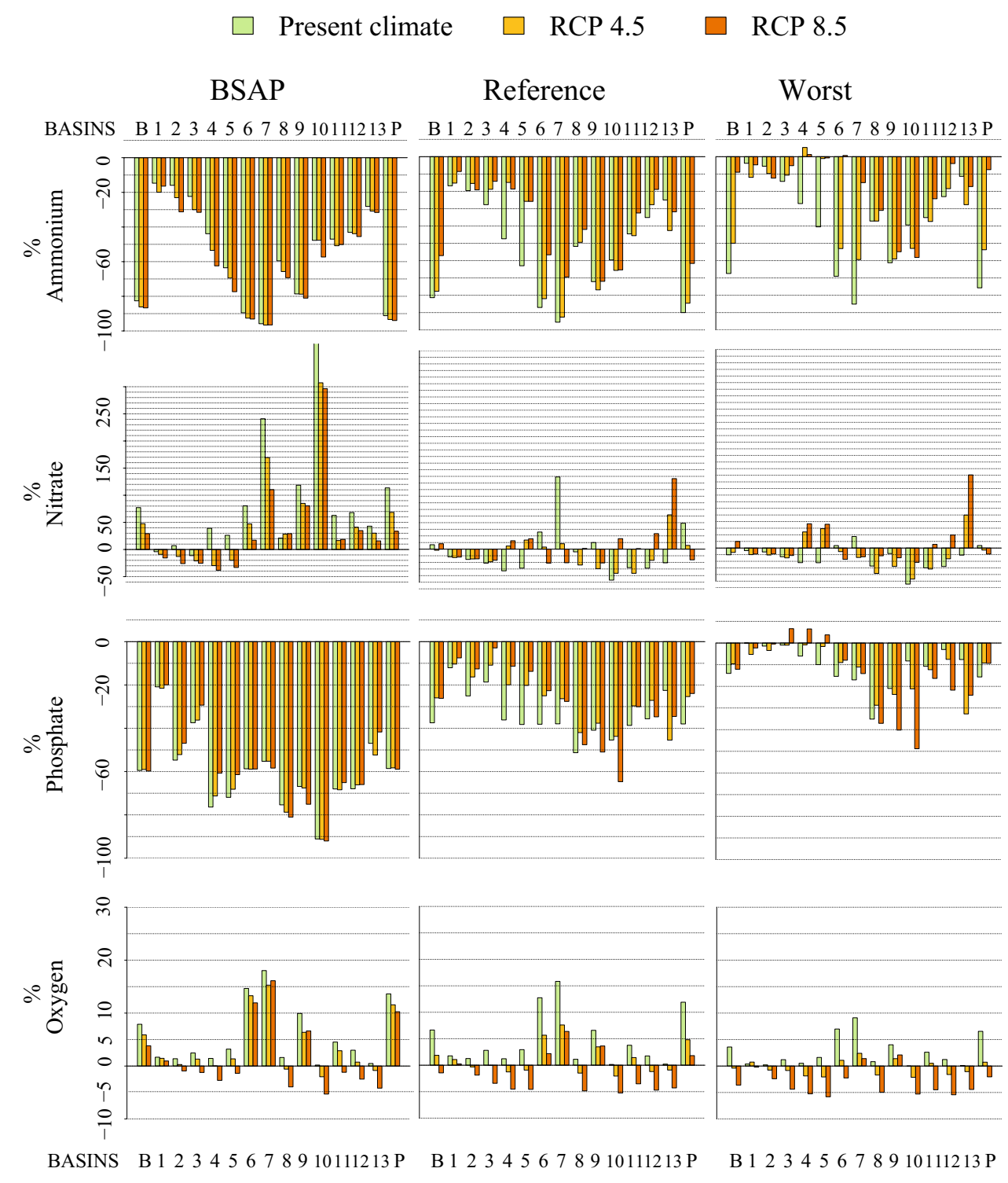

When BSAP is assumed, changes in biogeochemical variables in both climate change scenarios (either RCP 4.5 or RCP 8.5) are within an interval of $10 \%$ of the solid line indicated by the grey shaded area in Fig. 16, which means that the values do not differ statistically between present and future climates. In the Reference scenario, the spread is larger, and it is possible to distinguish that climate has now more influence (most of the changes are above the solid line) but still with absolute values lower than the changes obtained under present climate conditions (most of the properties are in the 3rd quadrant in the plot). The Worst scenario (particularly together with RCP 8.5), as mentioned before, counteracts the improvements in Baltic Sea ecological state. For this reason the changes in this particular scenario are generally smaller than in the other scenarios. There are however some exceptions. In the case of nitrogen fixation, it is noteworthy that under the Reference scenario, changes induced by future climate are not significant (compared with present climate conditions), but under the Worst scenario, climate change becomes important.

In summary, concerning the biogeochemical variables, the comparison between the different scenarios suggests that the impact of climate depends on the nutrient level. Under the BSAP the climate change impact is not significant. Increasing nutrient loads enlarges the vulnerability of the system to climate change and the past trend towards improved ecological state can be compromised.

Our results differ considerably from previous studies by (e.g. Meier et al. 2011a, b, 2012a, b). For instance, Meier et al. (2012b) concluded that the BSAP will improve water quality at the end of the century measured, for instance, by Secchi depth. However, they found that for the same targets larger reductions will be necessary compared to present 


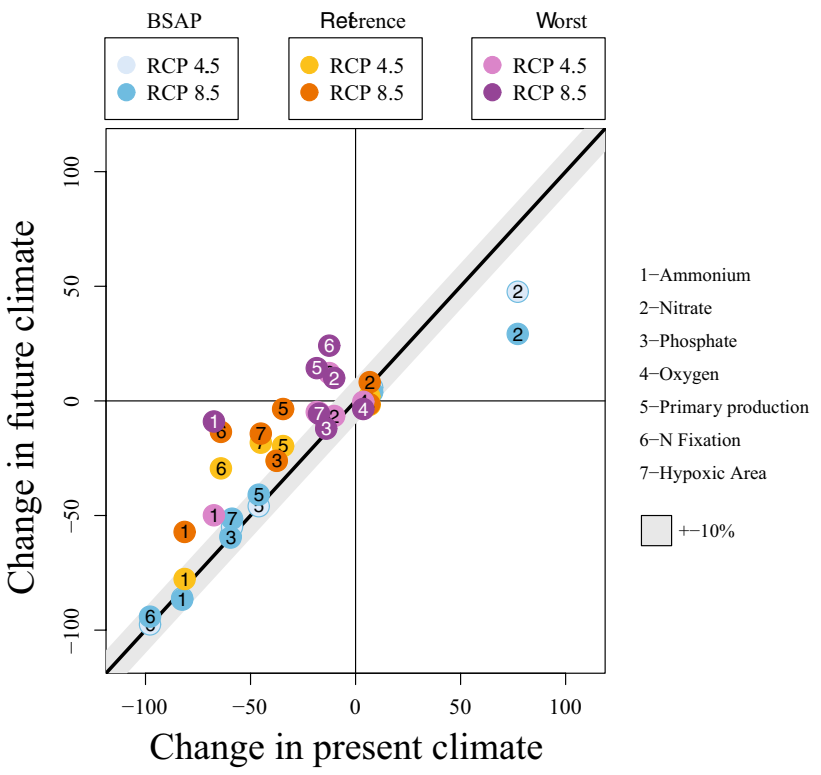

Fig. 16 Average changes (in \%) between future (2069-2099) and historical (1976-2005) periods in future vs. present climates for concentrations of ammonium, nitrate, phosphate and oxygen and for primary production, nitrogen fixation and hypoxic area. The grey shaded area corresponds to changes in the range between -10 and $+10 \%$

climate. Although differing GCMs (CMIP3 vs. CMIP5), RCMs (RCAO vs. RCA4-NEMO), versions of the Baltic Sea model and greenhouse gas emission scenarios (A1B and A2 vs. RCP 4.5 and RCP 8.5) were used, projected future climates in our and this previous study are similar (increased water temperature and runoff, decreased ice cover). Hence, the main reasons for the differing results in eutrophication response to nutrient load changes are the assumed nutrient loads during historical and future climates. The main differences in the nutrient loads assumptions are listed and discussed below.

1. For the Reference scenario of this study, we used observed BED nutrient load data until 2006 and after 2006, a climatological mean based on observed nutrient concentrations in river flow averaged for the period 2010-2012. Hence, for present climate simulations, in the Reference scenario, nutrient loads will not change after 2006. On the other hand, Meier et al. (2011b) assumed for their Reference scenario (REF) constant nutrient concentrations calculated from BED for 19691998 (Eilola et al. 2011) both during the historical (1960-2006) and future (2007-2100) periods.

2. The calculation of nutrient load changes in BSAP and a worst case scenario [called business-as-usual or BAU by Meier et al. (2012b)] were estimated by Gustafsson et al. (2011) as relative changes compared to the average of the reference period 1995-2002.
Table 1 Total nutrient loads from land and atmosphere to the Baltic Sea under present climate conditions

\begin{tabular}{llllll}
\hline & \multicolumn{2}{l}{$\begin{array}{l}\text { Re-calculated (Eilola et al. } \\
\text { 2009; Meier et al. 2012b) }\end{array}$} & & This study (see Fig. 4) \\
\cline { 2 - 3 } \cline { 5 - 6 } & $\begin{array}{l}\mathrm{P}[\mathrm{ktonP} \\
\left.\mathrm{year}^{-1}\right]\end{array}$ & $\begin{array}{l}\mathrm{N}[\mathrm{ktonN} \\
\left.\mathrm{year}^{-1}\right]\end{array}$ & & $\begin{array}{l}\mathrm{N}[\mathrm{ktonN} \\
\left.\mathrm{year}^{-1}\right]\end{array}$ & $\begin{array}{l}\mathrm{N}[\mathrm{ktonN} \\
\left.\mathrm{year}^{-1}\right]\end{array}$ \\
\hline Historical & 36 & 1054 & 56 & 1085 \\
BSAP & 23 & 871 & & 21 & 781 \\
Reference & 36 & 1054 & 33 & 811 \\
Worst (BAU) & 49 & 1519 & 42 & 937 \\
\hline
\end{tabular}

3. Meier et al. (2012b) calculated nutrient loads from the product of nutrient concentrations in rivers and volume flow, i.e. taking the impact of warming climate on increasing river flow in all three nutrient load scenarios (BSAP, REF and BAU) into account (Meier et al. (2012b), their Fig. 6).

4. Load changes by Gustafsson et al. (2011) were applied to total loads (not only to bioavailable fractions).

The results for present climate conditions are summarized in Table 1. Hence, for present climate conditions nitrogen loads after 2006 in the study by Meier et al. (2012a) would be considerably larger than in our study and were calculated to be even larger with increasing volume flows (Meier et al. (2012b), their Fig. 6). In future climate conditions, phosphorus and nitrogen loads under the worst case scenario called 'business-as-usual scenario (BAU) by Meier et al. (2012b), are much larger than the worst scenario of this study. It is however important to note that: in our study the impact of climate on nutrient loads in BSAP is not considered; in the model $30 \%$ of the river borne organic nitrogen supply is regarded as bioavailable but not listed here; historical periods for the analysis of changes are 1971-2000 and 1976-2005 in Meier et al. (2012b) and in this study, respectively, and in Meier et al. (2012b) the impact of nutrient load changes under present climate conditions was not investigated. In addition, nutrient loads during the historical period in the two discussed studies differ. In this study, we take the observed nutrient load reductions since the 1980s and the spin-up of the initial conditions for the water column and the sediment since 1850 into account. Indeed, nutrient loads averaged for the historical period are larger in this study compared to Meier et al. (2012b) causing for instance larger hypoxic area. When we calculate changes between future and historical climate we compare with an environmental state that is worse compared to the reference state by Meier et al. (2012b). Hence, in our study the improvements due to nutrient load reductions are much larger.

One shortcoming of the presented scenario simulations remains to be solved in forthcoming studies. Global mean 
sea level rise (GSLR) has been reported to have an impact on biogeochemical cycles in the Baltic Sea in high-end scenarios of about $1 \mathrm{~m}$ (Meier et al. 2017). This result would affect at least our scenario simulations based upon RCP 8.5 because the RCP 8.5 scenario might be consistent with a GSLR of $1 \mathrm{~m}$. However, our main conclusions of the impact of nutrient load reductions (in particular the BSAP) in present and future climates will very likely not be affected.

We have studied regional climate projections based upon only one GCM (MPI-ESM-LR). Hence, uncertainties due to model biases of the global model are not investigated. To estimate these uncertainties and its impact on biogeochemical cycles in the Baltic Sea under various nutrient load scenarios we will investigate four regionalized GCMs of CMIP5 in a forthcoming study.

\section{Conclusions}

From the model results of this study we draw the following conclusions:

1. Freezing present nutrient supply from land (Reference) will improve the ecological state of the Baltic Sea compared to the reference period 1976-2005 independent how future climate may evolve. However, a combination of high-end scenarios for nutrient loads (Worst) and climate (RCP 8.5) may partly counteract the improvements of past nutrient load reductions since the 1980s and may lead to reinforced eutrophication compared to 1976-2005.

2. Implementation of the BSAP together with negligible changes in climate will lead to a significant improved ecological state of the Baltic Sea.

3. Because of the long memory of biogeochemical cycles in the Baltic Sea (> 30 years) it is very important to perform transient simulations taking also past nutrient load evolution into account. The long response time scale causes changes far into the future. For instance, in case of the BSAP a new steady-state for phosphate in the water column will first be reached after 2060 and for nitrate it may take even longer.

4. We found large differences in our results compared to previously performed scenario simulations using the same model Meier et al. (2012a, b). Hence, the experimental setup and assumptions of nutrient load scenarios impact the results of the scenario simulations considerably. Also the definition of the reference period is very important for the magnitude and even the sign of the calculated changes because large changes during the historical period are found. Large differences between projections are caused by the various nutrient load sce- narios and whether climate change impacts the loads or not.

5. The impact of climate change (mainly warming) amplifies eutrophication and primary production. However, effects of changing climate within the range of considered greenhouse gas emission scenarios (RCP 4.5 and RCP 8.5), are smaller than effects of considered nutrient load changes (BSAP, Reference, Worst). The impact of climate change is larger for high nutrient conditions, i.e. larger for the Worst scenario than for the BSAP. In case of Worst the impact of warming may change the sign in the response of nitrate, oxygen concentration, primary production and nitrogen fixation.

Acknowledgements The research presented in this study is part of the Baltic Earth program (Earth System Science for the Baltic Sea region, see http://www.baltic.earth) and was funded by the BONUS BalticAPP (Well-being from the Baltic Sea applications combining natural science and economics) project which has received funding from BONUS, the joint Baltic Sea research and development programme (Art 185), funded jointly from the European Unions Seventh Programme for research, technological development and demonstration and from Swedish Research Council for Environment, Agricultural Sciences and Spatial Planning (FORMAS), Grant no. 942-2015-23. Support by FORMAS within the project "Cyanobacteria life cycles and nitrogen fixation in historical reconstructions and future climate scenarios (1850-2100) of the Baltic Sea" (Grant no. 214-2013-1449) and by the CERES project, which has received funding from the European Union's Horizon 2020 research and innovation programme under grant agreement no. 678193, is acknowledged. In addition, Sofia Saraiva would like to acknowledge the support by Fundação para a Ciência e a Tecnologia, Portugal (SFRH/BPD/120279/2016) in the later stage.

Open Access This article is distributed under the terms of the Creative Commons Attribution 4.0 International License (http://creativeco mmons.org/licenses/by/4.0/), which permits unrestricted use, distribution, and reproduction in any medium, provided you give appropriate credit to the original author(s) and the source, provide a link to the Creative Commons license, and indicate if changes were made.

\section{References}

Almroth-Rosell E, Eilola K, Hordoir R, Meier HM, Hall PO (2011) Transport of fresh and resuspended particulate organic material in the baltic sea a model study. J Mar Syst 87(1):1-12

Bergström S, Carlsson B (1994) River runoff to the baltic sea-19501990. Ambio 23(4-5):280-287

Boesch D, Hecky R, O’Melia C, Schindler D, Seitzinger S (2006) Eutrophication of Swedish seas, 1st edn. Swedish environmental protection agency, Berlin

Bumke K, Hasse L (1989) An analysis scheme for determination of true surface winds at sea from ship synoptic wind and pressure observations. Bound-Layer Meteorol 47(4-5):295-308

Detlef V Vuuren P, Morna I, Zbigniew WK, Nigel A, Terry B, Patrick C, Frans B, Henk H, Jochen H, Andries H, Alban K, Tom K, Reinhard M, Serban S (2011) The use of scenarios as the basis for combined assessment of climate change mitigation and 
adaptation. Global Environ Change 21(2):575-591 (special Issue on The Politics and Policy of Carbon Capture and Storage)

Dieterich C, Schimanke S, Wang S, Vli G, Liu Y, Hordoir R, Axell L, Höglund A, Meier H (2006) Evaluation of the SMHI coupled atmosphere-ice-ocean model RCA4-NEMO. Report Oceanography (RO), vol 47, 1st edn. SMHI, Norrköping

Donnelly C, Greuell W, Andersson J, Gerten D, Pisacane G, Roudier P, Ludwig F (2017) Impacts of climate change on european hydrology at 1.5, 2 and 3 degrees mean global warming above preindustrial level. Clim Change 143(1):13-26

Donnelly C, Arheimer B, Capell R, Dahne J, Strömqvist J (2013) Regional overview of nutrient load in Europe challenges when using a large-scale model approach, E-HYPE. Understanding fresh-water quality problems in a changing world., 1st edn. Proceedings of IAHS-IAPSO-IASPEI Assembly, Gothenburg, Sweden

Eilola K, Meier HM, Almroth E (2009) On the dynamics of oxygen, phosphorus and cyanobacteria in the baltic sea; a model study. $\mathrm{J}$ Mar Syst 75(1):163-184

Eilola K, Gustafsson BG, Kuznetsov I, Meier HEM, Neumann T, Savchuk OP (2011) Evaluation of biogeochemical cycles in an ensemble of three state-of-the-art numerical models of the Baltic Sea. J Mar Syst 88:267-284

Friedland R, Neumann T, Schernewski G (2012) Climate change and the baltic sea action plan: model simulations on the future of the western baltic sea. J Mar Syst 105:175-186

Gröger M, Dieterich C, Meier M, Schimanke S (2015) Thermal air-sea coupling in hindcast simulations for the north sea and baltic sea on the nw european shelf. Tellus Ser A, Dyn Meteorol Oceanogr 67:26911

Gustafsson B, Savchuk O, Meier H (2011) Load scenarios for ECOSUPPORT. Technical report 4. Baltic Nest Institute, Stockholm, Sweden

HELCOM (2007) Toward a Baltic Sea unaffected by eutrophication. Background document to Helcom Ministerial Meeting.Tech. rep. Helsinki Commission, Krakow, Poland

HELCOM (2013) Summary report on the development of revised Maximum Allowable Inputs (MAI) and updated Country Allocated Reduction Targets (CART) of the Baltic Sea Action Plan. Tech. rep, Helsinki Commission, Copenhagen, Denmark

Hordoir R, Meier HEM (2012) Effect of climate change on the thermal stratification of the baltic sea: a sensitivity experiment. Clim Dyn 38(9):1703-1713

Hundecha Y, Arheimer B, Donnelly C, Pechlivanidis I (2016) A regional parameter estimation scheme for a pan-european multibasin model. J Hydrol Reg Stud 6:90-111

Jacob D, Petersen J, Eggert B, Alias A, Christensen OB, Bouwer LM, Braun A, Colette A, Déqué M, Georgievski G, Georgopoulou E, Gobiet A, Menut L, Nikulin G, Haensler A, Hempelmann N, Jones C, Keuler K, Kovats S, Kröner N, Kotlarski S, Kriegsmann A, Martin E, van Meijgaard E, Moseley C, Pfeifer S, Preuschmann S, Radermacher C, Radtke K, Rechid D, Rounsevell M, Samuelsson P, Somot S, Soussana JF, Teichmann C, Valentini R, Vautard R, Weber B, Yiou P (2014) Euro-cordex: new high-resolution climate change projections for european impact research. Reg Environ Change 14(2):563-578. https://doi.org/10.1007/s1011 3-013-0499-2

Liu Y, Meier HEM, Eilola K (2017) Nutrient transports in the baltic sea - results from a 30-year physical-biogeochemical reanalysis. Biogeosciences 14(8):2113-2131. https://doi.org/10.5194/bg-142113-2017http://www.biogeosciences.net/14/2113/2017/

Meier HEM, Kauker F (2003) Modeling decadal variability of the baltic sea: 2. role of freshwater inflow and large-scale atmospheric circulation for salinity. J Geophys Res: Oceans 108(C11):3368
Meier M, Doescher R, Faxen T (2003) A multiprocessor coupled iceocean model for the baltic sea: application to salt inflow. J Geophys Res 108(C8):3273

Meier HEM, Andersson HC, Eilola K, Gustafsson BG, Kuznetsov I, Mller-Karulis B, Neumann T, Savchuk OP (2011a) Hypoxia in future climates: a model ensemble study for the baltic sea. Geophys Res Lett 38(24):124608

Meier M, Eilola K, Almroth-Rosell E (2011b) Climate-related changes in marine ecosystems simulated with a three-dimensional coupled physical-biogeochemical model of the baltic sea. Clim Res (CR) 48:31-55

Meier HEM, Andersson HC, Arheimer B, Blenckner T, Chubarenko B, Donnelly C, Eilola K, Gustafsson BG, Hansson A, Havenhand J, Hglund A, Kuznetsov I, MacKenzie BR, Mller-Karulis B, Neumann T, Niiranen S, Piwowarczyk J, Raudsepp U, Reckermann M, Ruoho-Airola T, Savchuk OP, Schenk F, Schimanke S, Vli G, Weslawski JM, Zorita E (2012a) Comparing reconstructed past variations and future projections of the baltic sea ecosystemfirst results from multi-model ensemble simulations. Environ Res Lett 7(3):034,005

Meier HEM, Hordoir R, Andersson HC, Dieterich C, Eilola K, Gustafsson BG, Höglund A, Schimanke S (2012b) Modeling the combined impact of changing climate and changing nutrient loads on the baltic sea environment in an ensemble of transient simulations for 1961-2099. Clim Dyn 39(9):2421-2441

Meier HEM, Müller-Karulis B, Andersson HC, Dieterich C, Eilola K, Gustafsson BG, Höglund A, Hordoir R, Kuznetsov I, Neumann T, Ranjbar Z, Savchuk OP, Schimanke S (2012c) Impact of climate change on ecological quality indicators and biogeochemical fluxes in the baltic sea: a multi-model ensemble study. AMBIO 41(6):558-573

Meier HEM, Höglund A, Eilola K, Almroth-Rosell E (2017) Impact of accelerated future global mean sea level rise on hypoxia in the baltic sea. Clim Dyn 49(1):163-172

Moss R, Edmonds J, Hibbard K, Manning M, Rose S, van Vuuren TDP, Carter Emori S, Kainuma M, Kram T, Meehl G, Mitchell J, Nakicenovic N, Riahi K, Smith S, Stouffer R, Thomson A, Weyant J, Wilbanks T (2010) The next generation of scenarios for climate change research and assessment. Nature 463(7282):747-756

Nakicenovic N, Swart R (2000) Emission scenarios. A special report of working group III of the intergovernmental panel on climate change, Oth edn. Cambridge University Press, Cambridge

Neumann T (2010) Climate-change effects on the baltic sea ecosystem: a model study. J Mar Syst 81(3):213-224

Neumann T, Eilola K, Gustafsson B, Muller-Karulis B, Kuznetsov I, Meier HEM, Savchuk OP (2012) Extremes of temperature, oxygen and blooms in the baltic sea in a changing climate. Ambio 41(6):574-585 (authorCount:7)

Omstedt A, Edman M, Claremar B, Frodin P, Gustafsson E, Humborg C, Hägg H, Mörth M, Rutgersson A, Schurgers G, Smith B, Wällstedt T, Yurova A (2012) Future changes in the baltic sea acid-base (ph) and oxygen balances. Tellus Series B, Chemical and physical meteorology 64:19,586 (authorCount:13)

O’Neill BC, Kriegler E, Riahi K, Ebi KL, Hallegatte S, Carter TR, Mathur R, van Vuuren DP (2014) A new scenario framework for climate change research: the concept of shared socioeconomic pathways. Clim Change 122(3):387-400

Ryabchenko VA, Karlin LN, Isaev AV, Vankevich RE, Eremina TR, Molchanov MS, Savchuk OP (2016) Model estimates of the eutrophication of the baltic sea in the contemporary and future climate. Oceanology 56(1):36-45

Saraiva S, Meier HEM, Andersson H, Höglund A, Dieterich C, Hordoir R, Eilola K (2018) Uncertainties in projections of the baltic sea ecosystem driven by an ensemble of global climate models. Earth System Dynamics Discussions 2018:1-30. https://doi. 
org/10.5194/esd-2018-16https://www.earth-syst-dynam-discu ss.net/esd-2018-16/

Schimanke S, Meier M (2016) Decadal-to-centennial variability of salinity in the baltic sea. J Clim 29(20):7173-7188

Stocker T, Qin D, Plattner GK, Alexander L, Allen S, Bindoff N, Breon FM, Church J, Cubasch U, Emori S, Forster P, Friedlingstein P, Gillett N, Gregory J, Hartmann D, Jansen E, Kirtman B, Knutti R, Krishna Kumar K, Lemke P, Marotzke J, Masson-Delmotte V, Meehl G, Mokhov I, Piao S, Ramaswamy V, Randall D, Rhein M, Rojas M, Sabine C, Shindell D, Talley L, Vaughan D, Xie SP (2013) Technical summary. In: Stocker T, Qin D, Plattner GK, Tignor M, Allen S, Boschung J, Nauels A, Xia Y, Bex V, Midgley P (eds) Climate change 2013: the Physical Science Basis. Contribution of working group I to the fifth assessment report of the intergovernmental panel on climate change. Cambridge University Press, Cambridge

Svendsen L, Pyhälä M, Gustafsson B, Sonesten L, Knuuttila S (2015) Inputs of nitrogen and phosphorus to the Baltic Sea. HELCOM core indicator report. Helsinki Commission, Helsinki
The BACC II, Team Author (2015) Second assessment of climate change for the Baltic Sea Basin. Springer International Publishing, Berlin

Väli G, Meier HEM, Elken J (2013) Simulated halocline variability in the baltic sea and its impact on hypoxia during 1961-2007. J Geophys Res: Oceans 118(12):6982-7000

van Vuuren DP, Edmonds J, Kainuma M, Riahi K, Thomson A, Hibbard K, Hurtt GC, Kram T, Krey V, Lamarque JF, Masui T, Meinshausen M, Nakicenovic N, Smith SJ, Rose SK (2011) The representative concentration pathways: an overview. Clim Change 109(1):5

Wang S, Dieterich C, Dscher R, Hglund A, Hordoir R, Meier HEM, Samuelsson P, Schimanke S (2015) Development and evaluation of a new regional coupled atmosphereocean model in the north sea and baltic sea. Tellus A: Dyn Meteorol Oceanogr 67(1):24,284. https://doi.org/10.3402/tellusa.v67.24284

Zandersen M, Pihlainen S, Hyytiinen K, Andersen HE, Jabloun M, Smedberg E, Gustafsson B, Bartosova A, Thodsen H, Meier M, Saraiva S, Olesen JE, Swaney D, McCrackin M (2018) Impacts of societal and climatic changes on nutrient loading to the baltic sea 